University of Louisville

ThinkIR: The University of Louisville's Institutional Repository

Electronic Theses and Dissertations

$12-2013$

\title{
XBP1 and MIST1 are not sufficient to induce the regulated secretory pathway in parotid cell lines.
}

Ian S. Pyle 1986-

University of Louisville

Follow this and additional works at: https://ir.library.louisville.edu/etd

\section{Recommended Citation}

Pyle, lan S. 1986-, "XBP1 and MIST1 are not sufficient to induce the regulated secretory pathway in parotid cell lines." (2013). Electronic Theses and Dissertations. Paper 1170.

https://doi.org/10.18297/etd/1170

This Master's Thesis is brought to you for free and open access by ThinkIR: The University of Louisville's Institutional Repository. It has been accepted for inclusion in Electronic Theses and Dissertations by an authorized administrator of ThinkIR: The University of Louisville's Institutional Repository. This title appears here courtesy of the author, who has retained all other copyrights. For more information, please contact thinkir@louisville.edu. 


\title{
XBP1 AND MIST1 ARE NOT SUFFICIENT TO INDUCE THE REGULATED SECRETORY PATHWAY IN PAROTID CELL LINES
}

\author{
By \\ Ian S. Pyle \\ B.A., Hanover College (Hanover, IN), 2008
}

\begin{abstract}
A Thesis
Submitted to the Faculty of the

School of Dentistry of the University of Louisville

In Partial Fulfillment of the Requirements

For the Degree of

Master of Oral Biology

Department of Oral Health and Rehabilitation

School of Dentistry

University of Louisville

Louisville, KY
\end{abstract}

December 2013 



\title{
XBP1 AND MIST1 ARE NOT SUFFICIENT TO INDUCE THE REGULATED SECRETORY PATHWAY IN PAROTID CELL LINES
}

\author{
By \\ Ian S. Pyle \\ B.A. Hanover College (Hanover, IN), 2008
}

A Thesis Approved on

October 1st, 2013

by the following Thesis Committee:

$\overline{\text { Dr. Douglas Darling, Thesis Director }}$

Dr. David Scott

Dr. Shuang Liang 


\section{DEDICATION}

I dedicate this thesis to my beautiful wife Miki and lovely daughter Ella Grace whose boundless love and fervent support have both inspired me and have been my succor during this time in my life.

I also dedicate this thesis to my grandmother who passed away during the induction of this work. She was smart, graceful, eloquent, and full of energy. 


\section{ACKNOWLEDGEMENTS}

Foremost, I thank my mentor Dr. Douglas Darling. His wisdom, attention to detail, and passion for scientific research is equally matched by the devotion he has to help his students succeed. Additionally, my research was only possible with the help from our lab manager, Anne Carenbauer. Her thorough knowledge and experience was invaluable. She also became a great friend. I also thank all our lab members for their help and friendship, Dr. S. G. Venkatesh, Melissa Metzler, Sara Perez, Farhad Sanati, and McKinley Soult.

Finally, I thank my parents for their love and support. I would not be successful today if it weren't for their philosophy of raising a lifelong learner and emphasizing independence. They were gracious in providing me with exceptional educational opportunities both in the classroom and via traveling the world. 


\section{ABSTRACT \\ XBP1 AND MIST1 ARE NOT SUFFICIENT TO INDUCE THE REGULATED SECRETORY PATHWAY IN PAROTID CELL LINES \\ lan S. Pyle \\ October $1^{\text {st }}, 2013$}

BACKGROUND: Xerostomia causes oral infections, tooth decay, and hindered digestion. Crucial to oral homeostasis is the salivary proteome. How these proteins are trafficked through secretory cells into secretory pathways is unknown. Abundant in the saliva is Parotid Secretory Protein (PSP), secreted through the regulated secretory pathway.

HYPOTHESIS: The addition of XBP-1 and Mist1, known for differentiation marker regulation, to ParC10 cells will improve stimulated secretion of PSP.

METHODS: Fusion clones were transiently or stably transfected into ParC10 cells. Media from non-stimulated and stimulated cells was harvested and luciferase activity was assayed.

RESULTS: Stimulated secretion of cypridina-PSP was not significantly higher than non-stimulated secretion; suggesting cypridina-PSP did not enter the regulated secretory pathway. Stably transfected ParC10 showed similar results. CONCLUSION: Cypridina-PSP, XBP-1, and Mist1 did not show stimulated secretion and thus, no cell differentiation was observed. The ParC10 cells lack a regulated secretory pathway. 


\section{TABLE OF CONTENTS}

PAGE

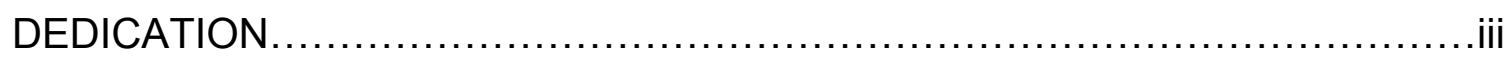

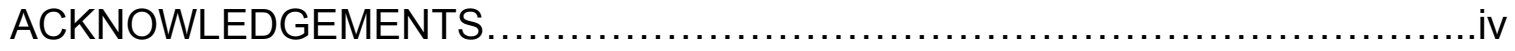

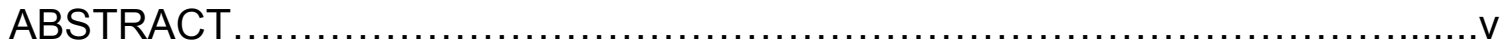

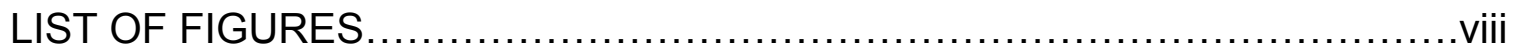

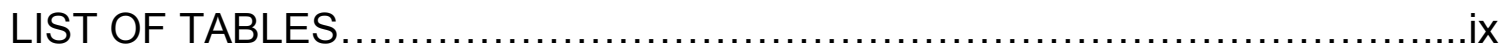

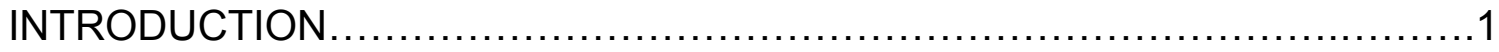

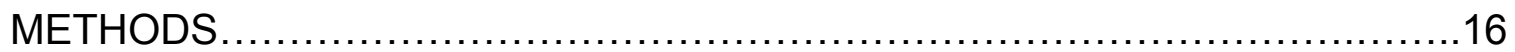

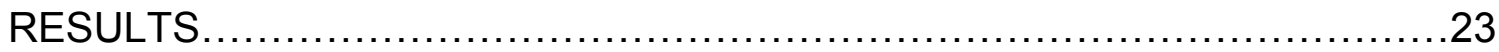

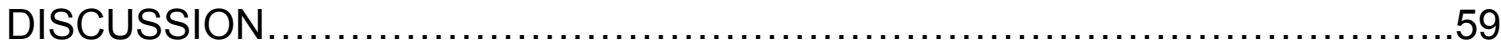

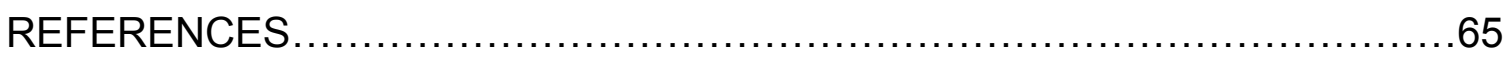

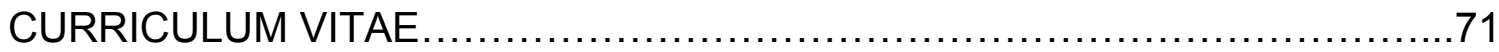




\section{LIST OF FIGURES}

FIGURE:

PAGE

1. Parotid Acinar Cell and Protein Trafficking Pathways..........................

2. Gene Expression of Transcription Factors in Primary Rat Parotid Gland Cells and ParC5 cells................................................................ 10

3. A Hypothetical Transcription Factor Network for PSP ........................11

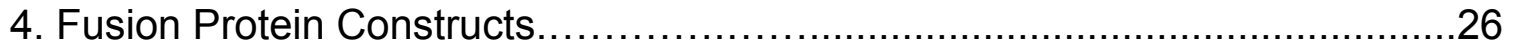

5. Hypothetical Raw Transfection Data......................................29

6. Hypothetical Stimulated / Basal Ratio Data....................................30

7. Gaussia-PSP Shows No Stimulated Secretion................................33

8. Cypridina-PSP and PSP-Cypridina Show No Stimulated Secretion..............38

9. Cypridina-PSP Shows No Stimulated Secretion................................39

10. Chromogranin B Has No Significant Effect on Stimulated Secretion..........42

11. Forskolin Does Not Improve Stimulated Secretion..........................45

12. Plasmid Maps of the PiggyBac Clones for Stable Transfection................47

13. Cell Line $E_{2}$ Shows No Stimulated Secretion...............................51

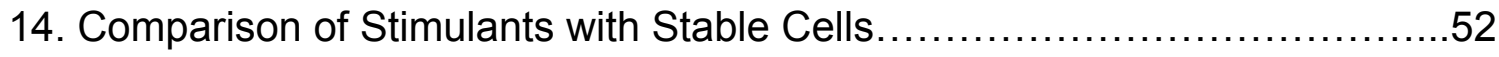

15. Comparison of Stable Cell Line Stimulated / Basal Ratio.....................55

16. Gel Elecrtrophoresis: Cell Lines D and $E_{2}$ Express XBP-1 $1 \ldots \ldots \ldots \ldots \ldots \ldots \ldots . \ldots \ldots$ 


\section{LIST OF TABLES}

$\begin{array}{lll}\text { TABLE } & \text { PAGE }\end{array}$

1. List of Clones Placed Into the pCMV 6.2 Vector.........................25

2. Stable Cell Lines and the Genes they Contain................................48 


\section{INTRODUCTION}

\section{Xerostomia}

Xerostomia, widely known as dry mouth, is a grievous condition affecting hundreds of millions of people worldwide (Rudney, 1995; Ship, Pillemer, \& Baum, 2002). Dry mouth is a condition in which the flow of saliva is diminished (Chan, Huang, Young, \& Lou, 2011; Rudney, 1995). Xerostomia can be caused by a number of factors or conditions, predominately: medication use, Sjögren's syndrome, and salivary gland damage or removal due to radiation therapy as cancer treatment (Baker et al., 2008; Chan, et al., 2011; Hadley et al., 2013; Shetty, Bhowmick, Castelino, \& Babu, 2012; Su et al., 2013; Zhang et al., 2013). The symptoms of dry mouth are: rampant oral infections, tooth decay, periodontitis, hindered digestion, and difficulty swallowing, speaking, and tasting food (Chan, et al., 2011; Gorr, Venkatesh, \& Darling, 2005; Shetty, et al., 2012; Zhang, et al., 2013). Though the fluid nature of saliva is important in the prevention of the symptoms of dry mouth, the proteins that inundate the saliva, produced and secreted by the parotid glands, play an essential role in host protection against infection, digestion, and overall oral homeostasis (Bhalla, Tandon, \& Satyamoorthy, 2010; Heo et al., 2013; Humphrey \& Williamson, 2001). It is important to study these proteins and how they are secreted to further 
the understanding of dry mouth, its future cure, and develop novel ways to alleviate its symptoms.

\section{The Salivary Glands and Specifically the Parotid Gland}

The salivary glands are responsible for the synthesis, storage, and secretion of saliva and all of its proteins. The major salivary glands are: the sublingual glands, the submandibular glands, and the parotid glands (Baker, 2010; Ho, Lin, Ann, Chu, \& Yen, 2011). There is also a multitude of minor salivary glands throughout the lower facial and upper neck region (Humphrey \& Williamson, 2001). In humans, the parotid glands are located laterally, on either side of the head, and are distal to the rami of the mandible, and are anterior to the ears (Ho, et al., 2011). The parotid gland is made of two distinct lobes, a superficial lobe and a deep lobe called the pharyngeal extension (Gervasio, D'Orta, Mujahed, \& Biasio, 2011). The superficial lobe accounts for two-thirds of the total parotid gland mass, and the pharyngeal extension comprises the remaining mass (Gervasio, et al., 2011). Though the facial nerve crosses over the parotid gland, it does not innervate the gland (Li, Li, Zhang, Yang, \& Wu, 2012). Rather, the parotid glands are innervated by the glossopharyngeal nerve (cranial nerve IX) (Gervasio, et al., 2011). The nerve innervation is solely autonomic and both para-sympathetic and sympathetic nerves stimulate the parotid gland.

In rats, the source of the parotid gland cells used in this study, the parotid glands are located subcutaneously near the midline of the neck lateral to the trachea. Like human parotid glands, the rat glands are innervated by the 
autonomic nervous system. Sympathetic and parasympathetic nerves stimulate the salivary glands to secrete salvia, which enters the mouth through ducts. The parotid gland duct is called Stensen's duct. Like all salivary ducts, Stensen's duct begins as a multi-branched body connecting to scores of acini, which are clusters of secretory cells, individually called acinar cells (Baker, 2010; Baker et al., 2010). Generally, single acinar cells secrete saliva and its proteins into the center of the acinus. The saliva then enters an intercalated duct which then leads to a striated duct which eventually leads to the salivary duct, i.e. Stensen's duct, and thus into the oral cavity.

\section{Saliva and Its Secretion}

Saliva is the liquid solution secreted into the oral cavity to help lubricate and prevent infection of the soft and hard oral tissues (Tran et al., 2013). Additionally, saliva helps break down food and begin the digestion process. Critical to the function of saliva is the multitude of proteins that are present $(\mathrm{Heo}$, et al., 2013).

Current research on saliva shows a salivary proteome of over 2,400 unique proteins (Cabras et al., 2013). Of the large number of proteins found in the saliva, the most abundant are amylase, Parotid Secretory Protein (PSP), a family of acidic and basic Proline Rich Proteins, histadin, and statherin (Darling, 2012; Helmerhorst \& Oppenheim, 2007). As with all biological systems, the proteome of the saliva is not constant. Instead, it is quite dynamic (Helmerhorst \& Oppenheim, 2007). From synthesis to secretion, the proteins undergo a myriad of changes ranging from deglycosylation, cleavage, and protein to protein 
complex formation (Helmerhorst \& Oppenheim, 2007). The protein makeup of the saliva is constantly changing depending on the environment of the oral cavity and the outer host environment. The saliva is also continually cycled as an individual swallows and new saliva is secreted into the oral cavity.

The water and mucus portions of saliva are major components, but henceforth this research paper focuses on the proteins of saliva. Before the salivary proteins can enter the oral cavity, they have to be sorted within the individual acinar cell. Exocrine gland acinar cells have several secretion pathways to traffic proteins within the cell and into the extracellular environment. In the parotid, these distinct secretion pathways are the major regulated secretory pathway, minor regulated pathway, apical and basolateral constitutive secretory pathway, and the constitutive-like secretory pathway (Castle, Huang, \& Castle, 2002; Darling, 2012; Perez, Rowzee, Zheng, Adriaansen, \& Baum, 2010). This research focuses on the difference between two of these pathways, the apical and basolateral constitutive secretory pathway (constitutive pathway) and the major regulated secretory pathway (regulated secretory pathway).

Constitutive secretion, that is secretion through the constitutive pathway, occurs in both the apical and basolateral ends of an exocrine cell. This type of secretion is continuous and the pathway is always turned on, in such a manner that secretion occurs regardless of the presence of a stimulus. Even when a cell is stimulated, the constitutive pathway is turned on and contributing to the total cell secretion. The proteins secreted via the constitutive pathway first enter secretory vesicles, which then travel directly from the trans-golgi network to the 
extracellular membrane for exocytosis in both the apical and basolateral ends of the cell (Gorr, et al., 2005; Kim, Gondre-Lewis, Arnaoutova, \& Loh, 2006).

Furthermore, the proteins that enter the constitutive pathway seem to differ from those found in other pathways. Most likely, these constitutive specific proteins are used for plasma and extracellular matrix communication; both regions found abutting the basolateral end of acinar cells.

Conversely, regulated secretion occurs only when the exocrine cell is exposed to a stimulus. In the parotid gland, the stimulus is either alpha or betaadrenergic neurotransmitters. Regulated secretion, also called stimulated secretion for the purpose of this thesis, is the release of proteins stored in dense core secretory granules (DCSG) and these proteins and occurs through the regulated secretory pathway (Kim, et al., 2006). During unstimulated secretion, which is through the constitutive pathway, the parotid glands produce and secrete about $20 \%$ of total saliva flow, the remaining secreted by the other salivary glands (Denny et al., 2008; Humphrey \& Williamson, 2001). However, during stimulated secretion, the salivary flow of parotid glands increases to $50 \%$ of the total flow (Denny, et al., 2008; Humphrey \& Williamson, 2001). Regulated sec Physiologically, stimulated secretion occurs during a meal, yet it is quiescent between meals (Huang, Castle, Hinton, \& Castle, 2001).

\section{Parotid Gland Acinar Cells}

Cargo proteins secreted into the parotid saliva are transcribed, translated, sorted, stored, and secreted by the parotid acinar cells (Venkatesh, Goyal, Carenbauer, \& Darling, 2011). These polarized cells are cone shaped and are 
found in clusters called acini (Baker, 2010) Figures 1A, 1B. In the middle of the parotid acinus is the duct where the saliva is secreted into and eventually through the Stensen's duct and into the oral cavity Figure 1A. Surrounding the acinar cells are fibroblast cells, nerve endings, and the capillary bed providing the blood supply. 
Figure 1: Parotid Acinar Cell and Protein Trafficking Pathways

A
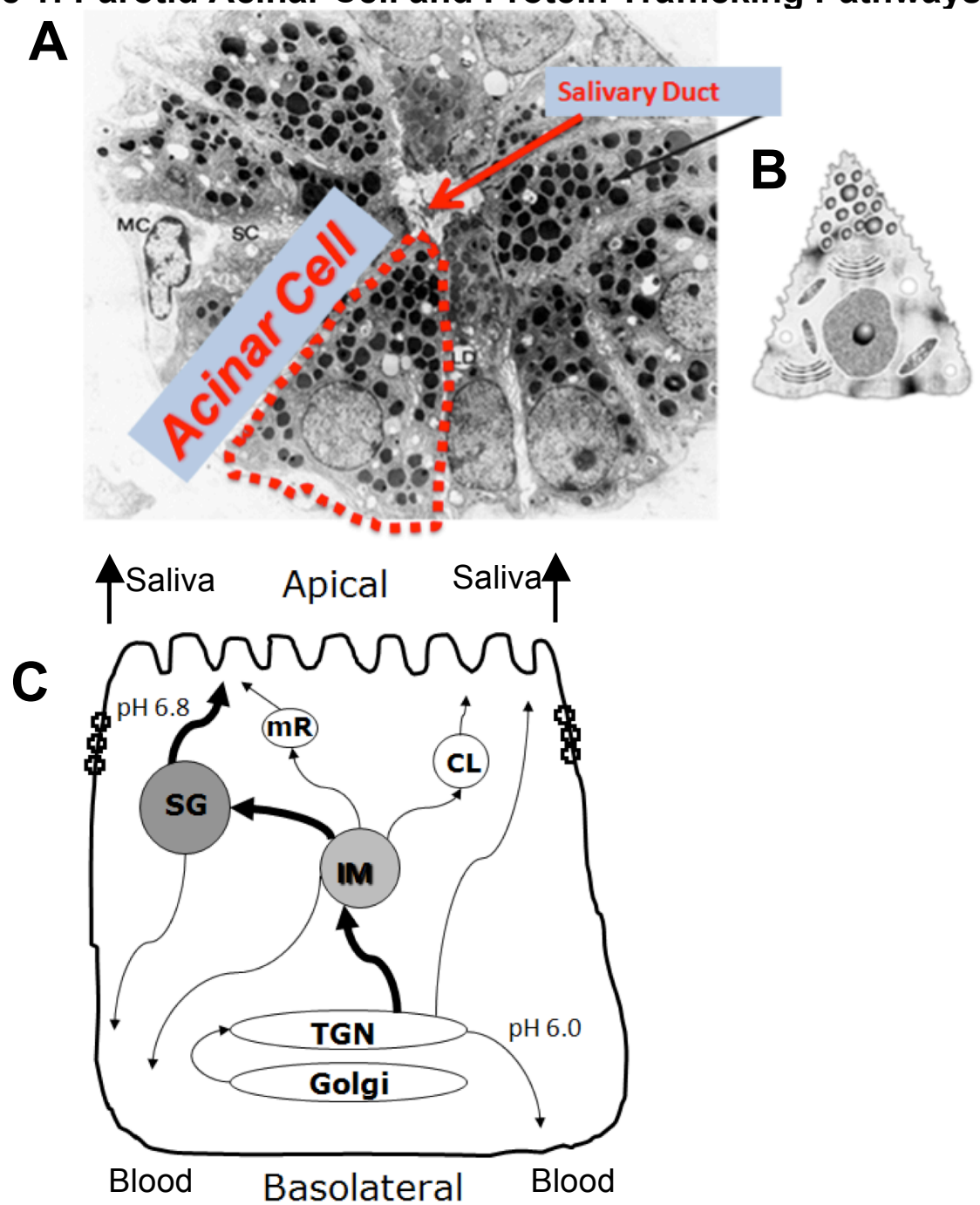

Figure 1: (A) This is a picture of an acinus (Mills, 2007). An acinar cell is highlighted in red and Stensen's duct (salivary duct) is in the center of the acinus. (B) A cartoon of an acinar cell (Mills, 2007). (C) A cartoon of a commensurate acinar cell(Gorr, et al., 2005). The bold arrow lines represent the regulated secretory pathway. The thin arrow lines represent the other various pathways including the constitutive pathway. Note the constitutive pathway is multidirectional, yet the regulated secretory pathway is uni-directional, specific to the apical end of the cell. 


\section{Immortalized Parotid Gland Acinar Cells (ParC10 cells)}

Ideally, primary rat parotid gland acinar cells would be used to study regulated secretion. Parotid cells are highly differentiated and are specialized cells performing very specific functions, such as saliva protein production and secretion. However, primary cells are difficult to isolate and even more difficult to sustain for the duration of a transfection experiment. Therefore, our experimental model used ParC10 cells, which are immortalized rat parotid gland acinar cells (Quissell, Turner, \& Redman, 1998). ParC10 cells are constantly used to study salivary gland secretion and have been studied extensively (Nelson, Manzella, \& Baker, 2013). ParC10In addition to ParC10 cells, this thesis refers to ParC5 cells, although they were not used in any experiments described in the results. Though the two cell lines grew up in separate wells and have some morphological and growing characteristic differences, they are essentially the same and were derived from the same immortalization experiment. ParC10 cells grow well in polystyrene flasks and in cell culture wells, while primary cells rapidly lose the differentiated phenotype in culture. The immortalized ParC10 cells do originate from primary rat parotid gland acinar cells, but are instead undifferentiated and have lost expression of some crucial proteins and transcription factors (Figure 2).

\section{Transcription Factors Missing from ParC10 Cells}

It is known that ParC10 cells express lower levels of RNA for proteins and transcription factors such as amylase and Mist 1 than primary rat parotid gland cells (Figure 2). Mist1 is a class B basic helix loop helix transcription factor (Yoshida et al., 2001). Mist1 and XBP-1 are two transcription factors thought to 
contribute to the regulation of expression of amylase (Figure 3). It is also known that both Mist1 and XBP-1 are important for the biogenesis of secretory granules and other machinery required for the regulated secretory pathway (Lee, Chu, Iwakoshi, \& Glimcher, 2005; Tian et al., 2010). Thus, the addition of Mist1, XBP1, or both to ParC10 cells may help initiate biogenesis of missing machinery necessary to the regulated secretory pathway. 
Figure 2: Gene Expression of Transcription Factors and Differentiation Markers of Primary Rat Parotid Gland Cells and ParC5 Cells

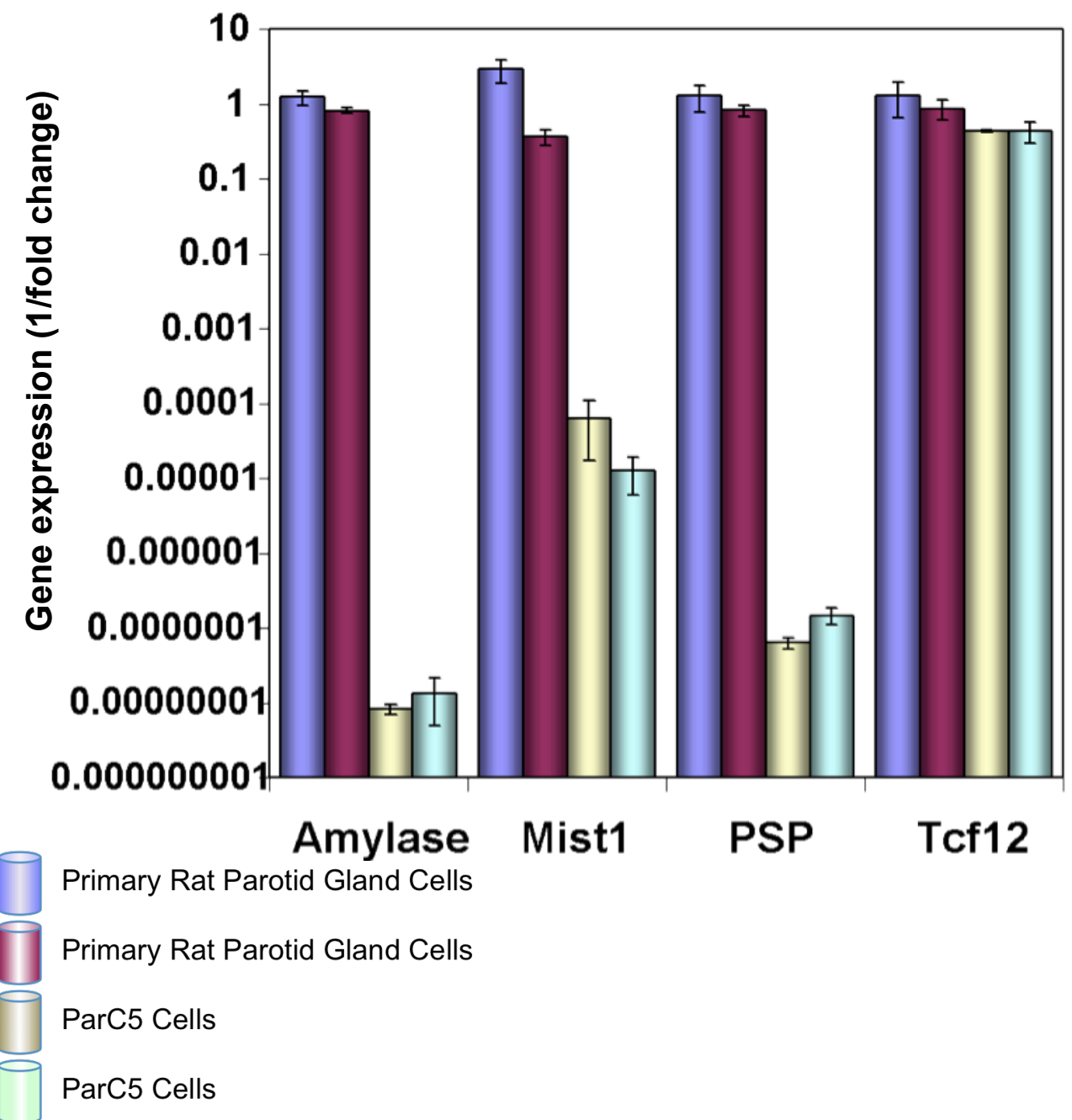

Figure 2: The above graph represents RNA expression levels of Amylase, Mist1, PSP, and Tcf12 in primary rat parotid gland cells (violet and purple colored bars) and ParC5 cells (beige and ice blue colored bars). The y-axis shows the RNA expression levels as a $1 /$ fold change starting from 10 at the top and going down 10 logs to $1 \times 10^{-9}$. ParC5 cells were derived from the same experiment as ParC10 cells. The conclusion of this graph is RNA expression levels for Amylase, Mist1, and PSP are exponentially less in ParC5 cells than in primary rat parotid gland cells. 
Figure 3: A Hypothetical Transcription Factor Network for PSP.

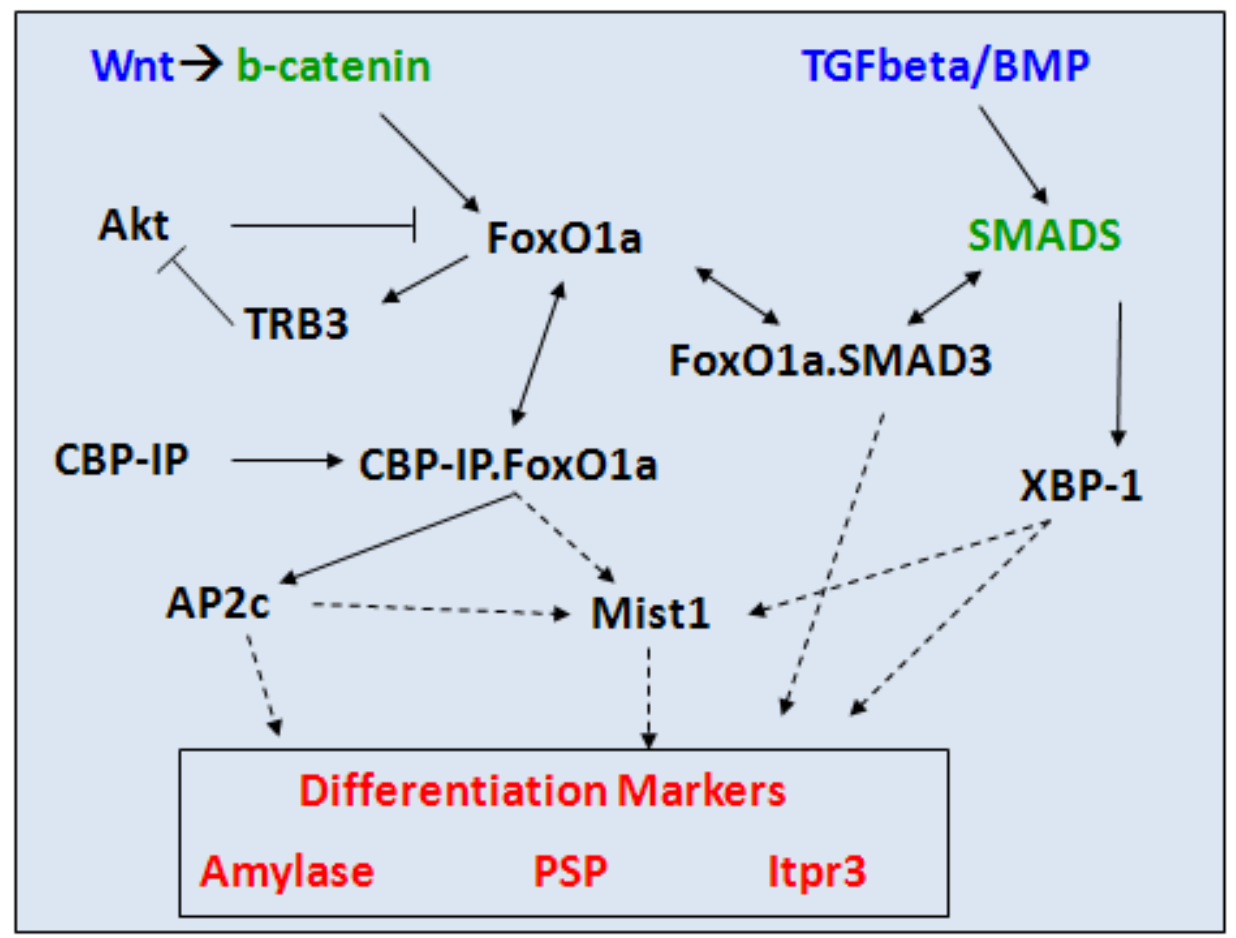

Figure 3: This figure shows a hypothetical transcription factor network. Various transcription factors, in black, help regulated the expression of the differentiation markers, in red. The hypothetical transcription factor network above suggests XBP and Mist1 are transcription factors involved in the expression of key parotid gland cell differentiation markers, amylase, PSP, and Itpr3. This is a working model in the Darling laboratory. 


\section{Regulated Secretory Pathway}

ParC10 cells are not polarized in culture and thus uni-directional regulated secretion cannot truly occur. However, the cells can be stimulated via an adrenergic agonist, which turns on the regulated secretory pathway in vivo. When the stimulant is added to ParC10 cells, for our experimental purposes, the operational definition of this type of secretion is: "stimulated secretion."

When stimulated in vivo, vesicles containing cargo proteins move to the apical end of the cell and the proteins are released. These specific vesicles are called dense-core secretory granules (DCSG). Until stimulated, these DCSGs are stored and continue to remain in the apical end of the cell, as seen in Figure 1A (Arvan \& Castle, 1986; Borgonovo, Ouwendijk, \& Solimena, 2006). The DCSGs are the small dark circles located in the apical, the pointed, end of the cell (Figure 1A) (Borgonovo, et al., 2006)

Contents of the DCSGs are released, via exocytosis, when Par-C10 cells receive a beta-adrenergic stimulus (Soltoff \& Hedden, 2010). A stimulant used in previous literature is isoproterenol, which is a beta-adrenergic agonist for the neurotransmitter epinephrine. The stimulus binds to the Beta-2 adrenergic receptors, which turn on a G-protein and adenylyl cyclase coupled pathway, thereupon up-regulating cyclic-adenosine monophosphate (cAMP) and activating

protein kinase A (PKA) (Soltoff \& Hedden, 2010; Takuma et al., 2013). This in turn induces the PKA cascade allowing the release of DCSGs.

Though the DCSGs are packed full of cargo proteins, only certain proteins are found in these vesicles (Gorr, et al., 2005). Hence, there are some cargo 
proteins that are distinguishable and are directed specifically into the regulated secretory pathway and into the specific granules. How this particular "protein sorting" occurs and how specific cargo proteins are directed into the regulated secretory pathway remains unknown (Courel et al., 2010; Dikeakos \& Reudelhuber, 2007; Folsch, Mattila, \& Weisz, 2009; Lord et al., 2011).

\section{Cargo Proteins of the Parotid Gland}

During stimulated secretion, the parotid glands contribute all the major salivary cargo proteins such as amylase, parotid secretory protein (PSP), and proline rich protein (PRP). These cargo proteins are transcribed and translated like all proteins. However, also like all proteins, after being directed into the endoplasmic reticulum (ER) via a signal sequence, the signal sequence of cargo proteins is cleaved by signal peptidase. Then protein continues to mature and moves to the trans-golgi network (TGN) and enters the regulated secretory pathway and is shepherded into secretory vesicles (Badr, Hewett, Breakefield, \& Tannous, 2007; Folsch, et al., 2009; Sobota, Ferraro, Back, Eipper, \& Mains, 2006). It is this process, in which the cargo proteins are sorted into the regulated secretory pathway, that is widely unknown (Courel, et al., 2010; Dikeakos \& Reudelhuber, 2007; Lord, et al., 2011). It is important to note that this process is unknown for all cargo proteins, secreted from all exocrine glands and this query is not limited to the parotid glands. It is currently postulated that certain proteins contain a sorting sequence or structure, different than the signal sequence which only directs the a nascent protein into the ER and is then cleaved, and it is this sorting sequence or structure that helps the cell recognize if the protein should 
be directed into the regulated secretory pathway or not (Gorr, et al., 2005).

However, it is important to note, this sequence or structure has not been found for proteins that enter the regulated secretory pathway, Such as PSP (Gorr, et al., 2005; Venkatesh, et al., 2011).

\section{Parotid Secretory Protein (PSP)}

Rat PSP, known as BPIFA2E, is a member of the bactericidal/permeability-increasing-fold (BPI-fold) protein superfamily (Abdolhosseini, Sotsky, Shelar, Joyce, \& Gorr, 2012; Bingle \& Bingle, 2011; Darling, 2012; Geetha, Venkatesh, Bingle, Bingle, \& Gorr, 2005). This superfamily includes the protein families: BPI protein, lipopolysaccharide binding protein (LBP), phospholipid transfer protein (PLTP), and cholesteryl ester transfer protein (CETP) (Abdolhosseini, et al., 2012; Darling, 2012). This protein is a member of the palate, lung, and nasal epithelium clone (PLUNC) gene family and, in humans, the gene is found on chromosome $20 \mathrm{q} 11$ (Abdolhosseini, et al., 2012; Bingle \& Bingle, 2011). Recent research suggests human PSP is a LBP protein, which indicates an anti-inflammatory role (Geetha, et al., 2005).

Additionally, it is documented that recombinant PSP shows anti-bacterial activity against the Gram-negative bacterium P. aeruginosa (Geetha, et al., 2005; Geetha, Venkatesh, Dunn, \& Gorr, 2003).

PSP is a protein secreted through the regulated secretory pathway that has antibacterial and anti-inflammatory properties (Geetha, et al., 2003). The protein is found in both human and rats, as well as pigs and bovine animals (Gorr, et al., 2005). PSP is only found in the saliva but not serum (Darling, 2012; 
Venkatesh, Tan, Gorr, \& Darling, 2007). Thus, PSP must enter the apical regulated secretory pathway since it is secreted uni-directionally out the apical end of the acinar cell towards Stensen's duct and not towards the basolateral end of the cell.

More evidence PSP enters the regulated secretory pathway is that it is found in DCSGs (Gorr, et al., 2005; Venkatesh, et al., 2011). Demonstrations have been made to show PSP binds to Phosphatidylinositol(3,4)bisphosphate (Ptdlns $\left.(3,4) P_{2}\right)$ very well (Venkatesh, et al., 2011). Ptdlns $(3,4) P_{2}$ is a lipid primarily found in the TGN and secretory granule membranes.

Of the major cargo proteins secreted by the parotid gland, PSP is a primary candidate for studying regulated secretion because, in vivo, it only enters the regulated secretory pathway and is only secreted when stimulated. However, how PSP enters this pathway is unknown. Furthermore, it is unknown how any protein enters the regulated secretory pathway of any acinar cell.

\section{Hypothesis}

The goal of this research is to establish a working experimental model to distinguish regulated secretion from other secretion pathways. With this goal in mind, we can use this experimental model to study how the specific salivary protein PSP enters the regulated secretory pathway. Considering that ParC10 cells lack transcription factors important to the function of the regulated secretory pathway, an important goal is to increase their expression and presence in the cells. The hypothesis is that the addition of XBP-1 and Mist1 to ParC10 cells will improve stimulated secretion of specific cargo proteins. 


\section{METHODS}

\section{Cloning}

The overall approach was to tag PSP with luciferase enzymes, making a quantitative and sensitive way to measure PSP secretion. It was necessary to synthesize DNA plasmid clones in the laboratory to construct the unique fusion proteins for our transfection experiments. The plasmid vectors were designed using Vector NTI software, which showed possible enzyme cut sites and the primers needed. The desired DNA fragments, were amplified by PCR (MJ Research PTC-200 thermocycler). This process consisted of 6 minutes of denaturation at $95^{\circ} \mathrm{C}, 33$ cycles of $95^{\circ} \mathrm{C}, 58^{\circ} \mathrm{C}$ and $72^{\circ} \mathrm{C}$, and an extension time of 10 minutes at $72^{\circ} \mathrm{C}$. The PCR product was confirmed by agarose gel electrophoresis and then cut out of the gel and purified using a Qiagen QIAquick Gel Extraction Kit.

Then, the purified PCR product was digested with appropriate enzymes, specific to the DNA fragment and the vector, and ligated into the vector using the thermocycler. The vectors were then transformed separately into Invitrogen One Shot Top 10 chemically competent bacterial E. coli cells. The cells were put onto a Luria Bretani broth (LB)/agar plate with ampicillin and left to incubate overnight at $37^{\circ} \mathrm{C}$. Colonies were picked and placed on a master plate and inoculated in $10 \mathrm{~mL}$ of LB/ampicillin media over night in a shaker at $37^{\circ} \mathrm{C}$. The following day a 
miniprep (Promega Wizardplus SV Miniprep kit) was performed per the manufacturers instructions to purify the plasmids. The plasmids were then digested with an enzyme or enzymes to cut the vector in a way to easily identify whether the DNA fragment was ligated correctly into the vector. This process usually produced a small and large fragment, which produces bands easy to distinguish on a gel. The successful plasmids were then sequenced at the University of Louisville Nucleic Acid Sequencing CGeMM core. Once the sequences were verified, the colonies with the correct sequences were picked from the master plate and inoculated in $50 \mathrm{~mL}$ of LB/ampicillin media overnight in a shaker at $37^{\circ} \mathrm{C}$. The plasmids were purified using a QIAgen Plasmid Midi Kit. The final plasmids were sampled in a nanodrop machine to verify no protein contamination, $(\lambda 260 / 280>1.80)$ and the amount of DNA in $\mathrm{ng} / \mu \mathrm{L}$.

\section{ParC5 Media Solution}

The optimal solution for culturing ParC10 cells is ParC5 media, identical to the media used for culturing ParC5 cells. One liter of ParC5 media solution contains: $950 \mathrm{~mL}$ double-distilled $\mathrm{H}_{2} 0 ; 10 \mathrm{~mL}$ of insulin-tranferrin-selenium-X (Invitrogen); $1 \mathrm{~mL}$ of $1 \mathrm{mM}$ hydrocortisone; $30 \mu \mathrm{L}$ of $1 \mathrm{mg} / \mathrm{mL}$ retinoic acid solution; $20 \mu \mathrm{L}$ of $0.1 \mathrm{mM}$ T3 solution; $50 \mu \mathrm{L}$ of $1.0 \mathrm{mg} / \mathrm{mL} E G F, 1 \mathrm{~mL}$ of $200 \mathrm{mM}$ L-Glutamine, $1 \mathrm{~mL}$ of $50 \mathrm{mg} / \mathrm{mL}$ gentamicin; $1 \mathrm{~mL}$ of Trace Element Solution (MPBiomedical); $5 \mathrm{~mL}$ of Penn/Strep (Invitrogen); $25 \mathrm{~mL}$ of fetal bovine serum (FBS); $1.25 \mathrm{~g}$ of $\mathrm{NaHCO}_{3}$; and $15.6 \mathrm{~g}$ of Dulbecco's Modified Eagle Medium-F12. The solution is adjusted to a $\mathrm{pH}$ of 7.3 . 


\section{Passaging Cells}

ParC10 cells were grown in either a T-25 or T-75 flask in either 5 or $10 \mathrm{~mL}$ of ParC5 media respectively. During growth, the media was exchanged for fresh media dependant on the $\mathrm{pH}$, determined by color of media, or amount of debris found in the flask. Cells were passaged when $60-75 \%$ confluent. To passage the cells, the flask was moved to a sterile Forma Scientific laminar flow hood. The media was aspirated, and $1 \mathrm{~mL}$ or $0.5 \mathrm{~mL}$ of trypsin was added to a T-75 flask or T-25 flask, respectively. The flask was moved to a New Brunswick Scientific Excella Eco 170 incubator with $5 \% \mathrm{CO}_{2}$ and a temperature of $37^{\circ} \mathrm{C}$, and incubated for 4 minutes. 3 or $1.5 \mathrm{~mL}$ of ParC5 media was added to the T-75 or T25 flask respectively and the cell-containing solution was pipetted up and down to break up the cells. A sample of the cell solution was then stained with $50 \%$ trypan blue and counted using a Reichart Bright-Line hemocytometer while looking through an Olympus CK2 microscope set at 10X magnification. The resulting cell count was then calculated for cells per $\mathrm{mL}$ and the desired cell seed amount was placed into wells. A sample of the cell solution was placed into a new flask to complete the passaging process and begin growing a new passage number of cells.

\section{Transfection}

$500 \mu \mathrm{L}$ of ParC5 media was placed in each well of a sterile 24 well plate (Corning $15.6 \mathrm{~mm}$ diameter wells). ParC10 cells were passaged and counted and were seeded at either $30 \mathrm{k}$ or $20 \mathrm{k}$ cells per well, depending on the particular experiment. The cells were allowed to incubate at $37^{\circ} \mathrm{C}$ overnight with $5 \% \mathrm{CO}_{2}$. 
The following day, the media was changed and fusion-protein-expressing plasmids were diluted in Dulbecco's Modified Eagle Medium (DMEM) to the appropriate amounts for a total of either $500 \mathrm{ng}$ or $200 \mathrm{ng}$ of DNA per well. For control, pBluescript II KS (+) was used as a filler DNA to maintain a consistent DNA mass. The plasmids were then added to the wells along with a transfection lipid reagent, either lipofectamine $₫$ or FuGENE HD $®$. FuGENE HD $®$ was used in a ratio of 1:8, DNA to lipid reagent, respectively. The cells were allowed to incubate at $37^{\circ} \mathrm{C}$ overnight in the incubator with $5 \% \mathrm{CO}_{2}$. The following day, the media was aspirated and the cells were prepared for a media harvest.

\section{Transfection Media Harvest}

The cells were washed with ParC5 media five times; incubated at $37^{\circ} \mathrm{C}$ with $5 \% \mathrm{CO}_{2}$ for 5 minutes three times, then again for 30 minutes, and once more for 5 minutes. The final wash media was aspirated and ParC5 media was then added to the cells and the plate was incubated at $37^{\circ} \mathrm{C}$ with $5 \% \mathrm{CO}_{2}$ for thirty minutes. Following the incubation, $400 \mu \mathrm{L}$ of the media was collected as a basal secretion sample. The sample was centrifuged at $\sim 300 \mathrm{~g}$ for 10 minutes to pellet any stray cells. $300 \mu \mathrm{L}$ of the top basal secretion sample was collected into a $1.5 \mathrm{~mL}$ Eppendorf tube and stored in $4^{\circ} \mathrm{C}$ until assay. The remaining $100 \mu \mathrm{L}$ of media in the 24 well plate was aspirated and the $500 \mu \mathrm{L}$ of Parc5 media was added to each well and the plate was incubated at $37^{\circ} \mathrm{C}$ with $5 \% \mathrm{CO}_{2}$ for five minutes for a wash. The wash media was aspirated and $500 \mu \mathrm{L}$ of ParC5 media containing a stimulant was added to each well. The stimulated media was prepared by adding isoproterenol $(30 \mu \mathrm{M})$, forskolin $(10 \mu \mathrm{M})$, carbachol $(100$ 
$\mathrm{mM}$ ), or a combination of these stimulants. Isoproterenol is an epinephrine agonist and turns on the cAMP pathway by binding to the beta-adrenergic receptor, a cellular membrane surface protein. Similarly, forskolin, turns on the CAMP pathway, but within the cell. The plate was incubated at $37^{\circ} \mathrm{C}$ with $5 \%$ $\mathrm{CO}_{2}$ for thirty minutes. Following the incubation, $400 \mu \mathrm{L}$ of the media was collected into a $1.5 \mathrm{~mL}$ Eppendorf tube as a stimulated secretion sample. The sample was spun at $\sim 300 \mathrm{~g}$ for 10 minutes to pellet any stray cells. $300 \mu \mathrm{L}$ of the top stimulated secretion sample was collected into a $1.5 \mathrm{~mL}$ Eppendorf tube and stored at $4^{\circ} \mathrm{C}$ until assay

\section{Assay}

To assay the samples of a media harvest, $20 \mu \mathrm{L}$ amounts of each harvested media sample was loaded onto a Perkin-Elmer 96 well OptiPlate in duplicate. A Berthold Centro XS3 LB 960 Luminometer was washed with 70\% $\mathrm{EtOH}$ and dionized $\mathrm{H}_{2} \mathrm{O}$ and then primed with either cypridina or gaussia luciferase reagent. The relative light unit $(R L U)$ data were displayed and recorded using MikroWin 2000 software.

\section{Stable Cell Creation}

To create the stable cell lines, the desired genes, i.e. Cypridina-PSP, Cypridina (Cluc-2), XBP, and Mist1 were cloned into the PBQM812-A1 PiggyBac Tranposon system vector (System Biosciences). The PiggyBac Transposon system transposes its cloned-in gene into the genome of the transfected cell. Gene expression can be turned on in the presence of cumate and turned off when the cumate is removed via the cumate switch. The PiggyBac system also 
transposes a puromycin resistant gene, so successfully transfected and transposed cells will live in the presence of puromycin. Finally, the system includes a GFP expressing gene, turned on in the presence of cumate. This feature gives the user the ability to see successful transposition using a confocal microscope.

Once the Cypridina-PSP, Cluc-2, XBP, and Mist1 PiggyBac plasmids were cloned, they were transfected into ParC10 cells, alone or in combination; including an empty PiggyBac plasmid for a control. The lines and their respective combinations are listed in the Results section. The cells were then put through a series of increasing puromycin concentrations to select for the successfully transfected and transposed cells. Ultimately, the cell lines were checked for successful transposition via the confocal microscope. Then, they were placed in liquid nitrogen tanks for long-term storage, or used immediately for secretion experiments.

\section{Stable Cell Secretion Experiment}

The cells were initially plated at $30 \mathrm{k}$ cells per well. The cells were grown in regular ParC5 media for six hours. Then, the media was aspirated and fresh ParC5 media containing $3 \mu \mathrm{g} / \mathrm{mL}$ of Puromycin and $10 \mu \mathrm{g} / \mathrm{mL}$ of Cumate was added until the cells were ready for harvest. The puromycin is necessary because the PiggyBac vector transposes a puromycin resistant gene to help select for just stably transfected cells. The Cumate in the media turns on the Cumate Switch vector so the cells can begin expression of the protein or proteins inserted into the cell. 


\section{rtPCR}

Reverse transcriptase was performed using the High Capacity cDNA Reverse Transcriptase Kit from Applied Biosystems per the manufacturer's instructions. A control tube was made without the reverse transcriptase enzyme. The results were verified on an agarose gel.

\section{Preparation of Agarose Electrophoresis Gel}

DNA samples were analyzed using gel electrophoresis. $1 \%$ agarose electrophoresis gels were made by combining $40 \mathrm{~mL}$ of double de-ionized water, $10 \mathrm{~mL}$ of $5 \mathrm{x}$ Tris/Borate/EDTA (TBE) buffer, and $0.5 \mathrm{~g}$ of ME agarose in an Erlenmeyer flask. The mixture was heated in an Amada RadaRange microwave oven for 2 minutes, pausing to swirl the flask at 30 -second intervals. After warming, $6 \mathrm{uL}$ of ethidium bromide was added to the mixture and it was then poured into the gel apparatus. A gel comb was inserted to create slots in the gel and the mixture was left to cool and harden. Once solid, 6x-loading dye was added to each sample and then samples and $1 \mathrm{~kb}+$ molecular weight marker DNA ladder (Invitrogen) were added into the gel slots. The gel was run using a FischerBiotech 105 electrophoresis system set to 148 , or 48 volts for low melt gels, and left for 30 minutes to 2 hours. For analysis, gels were placed on a Fishcer Biotec FBTI 816312 nm ultraviolet transilluminator and the picture was captured using the Stratagene Eagle Eye system. 


\section{RESULTS}

\section{Synthesis of Clones used for Transient Transfections}

The ability to measure a specific protein being secreted out of an exocrine cell was crucial to designing the experiments used in this research. The other key was using a secreted protein well known for a specific secretion pathway. Luciferase proteins, which are readily attached to other proteins via cloning, emit light when interacting with specific substrates, e.g, luciferin and ATP. The light produced from the luciferase protein and substrate interaction can be easily measured. Thus, a luciferase protein was attached to Parotid Secretory Protein (PSP), which is well documented for only entering the regulated secretory pathway in parotid gland cells, as mentioned in the introduction. Clones are inserted into cells by performing a transient transfection. The clone is part of a plasmid vector, which enters the nucleus of a cell to be transcribed and translated. After secretory cells manufacture this fusion protein, it is then secreted into the culture media and the amount of released protein is measured.

The cells used in the following experiments were ParC10 cells. Though these cells were derived from a rat parotid gland, they had been immortalized and are to a great extent, undifferentiated. They are polar when grown on transwell filters. In vivo, PSP is secreted through the regulated secretory pathway, but in the ParC10 cells the pathway for secretion of the fusion protein is unknown. 
Despite being undifferentiated, adding a neurotransmitter agonist to the cells may stimulate them to secrete the fusion protein in a more in-vivo like manner. Particularly, the amount of PSP being secreted should increase once a stimulus has been added. We used the term "stimulated" when the neurotransmitter agonist was added to the cells. When no stimulant was present, we used the term "basal," because in-vivo, constitutive secretion occurs perpetually and at lower amounts. Therefore, basic cell functions critical to our research can be controlled and manipulated.

The specific luciferase proteins we used in our transfections are Gaussia luciferase and Cypridina luciferase. Gaussia luciferase originates from the copepod called Gaussia Princeps (Welsh, Patel, Manthiram, \& Swartz, 2009). It is a marine crustacean that glows from bioluminescence, caused by the Gaussia protein interacting with a substrate. Similar to the Gaussia protein is Cypridina luciferase. Cypridina originates from the ostracod called Cypridina noctiluca and produces a bioluminescent protein like the Gaussia protein, which also glows in the presence of a substrate (Nakajima, Kobayashi, Yamagishi, Enomoto, \& Ohmiya, 2004).

The clones and their respective plasmid vectors used for all transient transfections are listed in Table 1 and Figure 4. The corresponding protein names are listed in column 4 of Table 1. Each clone in Table 1 displays the correct sequence and was transformed into One Shot Top10 chemically competent bacterial Escherichia coli (E. coli) cells. 


\section{Table 1}

List of Clones Placed Into the pCMV 6.2 Vector

\begin{tabular}{|l|l|l|l|}
\hline $\begin{array}{c}\text { EXPRESSION } \\
\text { VECTOR }\end{array}$ & \multicolumn{1}{|c|}{ INSERT } & \multicolumn{1}{|c|}{ FINAL CLONE } & \multicolumn{1}{|c|}{ PROTEIN NAME } \\
\hline pcDNA 6.2 & PSP-Gaussia & ratPSP-Gaussia & PSP-Gau \\
\hline pcDNA 6.2 & SS-rPSP- $\Delta$ SS-Gaussia & pcDNA 6.2-ratSSp- $\Delta$ SSGAU & SSp $\Delta$ SSgau \\
\hline pCMV & Gaussia & pCMV-Gluc & Gluc \\
\hline pcDNA 6.2 & rPSP- $\Delta$ SS-Cypridina & pcDNA 6.2-ratPSP- $\Delta$ SS & PSP- $\Delta$ SS-CLuc-2 \\
\hline pcDNA 6.2 & SSp- $\Delta$ SS-Cypridina & pcDNA 6.2-SSratPSP- $\Delta S S-C L u c-2$ & SSp- $\Delta S S-C L u c-2$ \\
\hline pcDNA 6.2 & Cypridina- $\Delta$ SS-rPSP & pcDNA 6.2-CYP- $\Delta S S$ ratPSP & CYP- $\Delta S S-P S P$ \\
\hline pCMV & CLuc-2 (Cypridina) & pCMV-CLuc-2 & CLuc-2 \\
\hline
\end{tabular}

Table 1: The clones listed in table 1 are represented as diagrams in Figure 4.

"SS" refers to the signal sequence of the protein and " $\Delta S S$ " refers to the deletion of the signal sequence of the protein. 
Figure 4: Fusion Protein Constructs

PSP-Gaussia

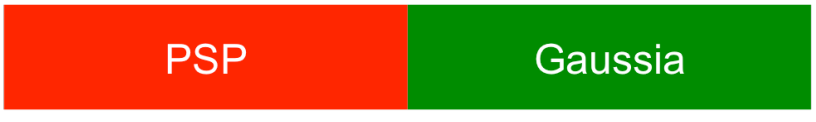

SSpDSSgaussia

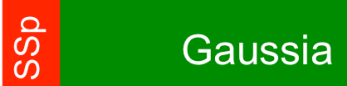

Gluc

Gaussia

PSP-DSS-Cluc-2

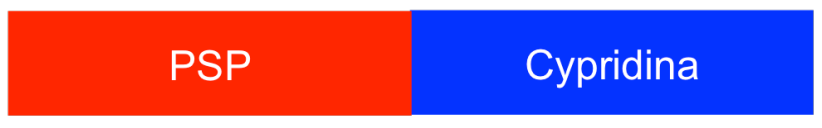

SSp-DSS-Cluc-2

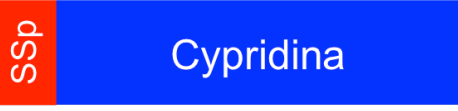

Cyp-DSS-PSP

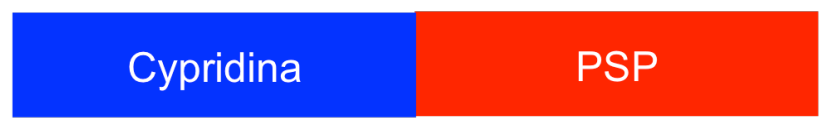

Cluc-2

\section{Cypridina}

Figure 4. The above figure represents the various fusion proteins used for the transient transfections performed for this research paper. The expression vectors and final protein names can be found listed in Table 1 and each clone shares the same common letter identifier. The proteins fused to the $\mathrm{C}$ terminus of other proteins are without their signal sequence (SS). 


\section{Measuring Regulated Secretion}

Regulated secretion is defined as the release of intracellular and vesicle bound proteins or chemicals to the extracellular space via the regulated secretory pathway. To interpret regulated secretion numerically, the stimulated relative light unit (RLU) values were divided by the unstimulated RLU values, and the resulting quotient is a ratio, which can help interpret the difference between basal and regulated secretion. Additionally, the ratio derived (stimulated divided by unstimulated) controls for well-to-well variation for transfection efficiency since each experiment is run with triplicate wells. The analyses of the experiments in this paper define basal secretion, as a ratio of one because the basal secretion divided by itself is one. Conversely, stimulated secretion is operationally defined as a value higher than one. Stimulated secretion if present always includes the perpetual constitutive secretion, which never turns off, even if stimulated. Thus, stimulated secretion is any ratio higher than one, while one is equal to the basal secretion.

Figure 5 represents a hypothetical graph representing the raw data from a secretion experiment. Both the basal and stimulated raw values (RLU or relative light units) are shown for Cypridina-PSP and the negative control, Cypridina alone (CLuc-2). The important point to note is the values for both the basal and stimulated CLuc-2 are equal. However, the values for the basal and stimulated Cypridina-PSP differ; basal Cypridina-PSP is lower and stimulated CypridinaPSP is higher by four fold. 
Figure 6 represents a hypothetical graph based on the graph in figure 5 . Figure 6 displays the ratio, the result of dividing the stimulated RLU by the basal RLU for both Cypridina-PSP and Cypridina alone. In Figure 6, the Cypridina alone ratio is one, because the stimulated value is equal to the basal value. In theory, the stimulated Cypridina alone RLU value represents only basal secretion because the stimulus does not evoke a response form the regulated secretory pathway, but basal secretion continues regardless of the presence of a stimulus. Though the Cypridina alone expressing cells are stimulated, the Cypridina alone protein only enters the perpetual constitutive pathway and not the regulated secretory pathway. Conversely, the ratio of stimulated Cypridina-PSP RLU divided by basal Cypridina-PSP RLU equals four, because the stimulated value is about four times the quantity of the basal value. Thus, the stimulus does evoke a response in the regulated secretory pathway, and the basal secretion continues regardless of the presence of a stimulus.

In the graph in Figure 6, a green line set at the basal/stimulated ratio of one represents the defining point at which the secretion occurring is either basal, below the green line, or stimulated, above the green line. Since Cypridina-PSP shows a ratio above one and above the green line, basal and stimulated secretion is occurring. Since Cluc-2 shows a ratio of one, and an average just at the green line but not above it, only basal secretion is occurring. 
Figure 5: Hypothetical Raw Transfection Data

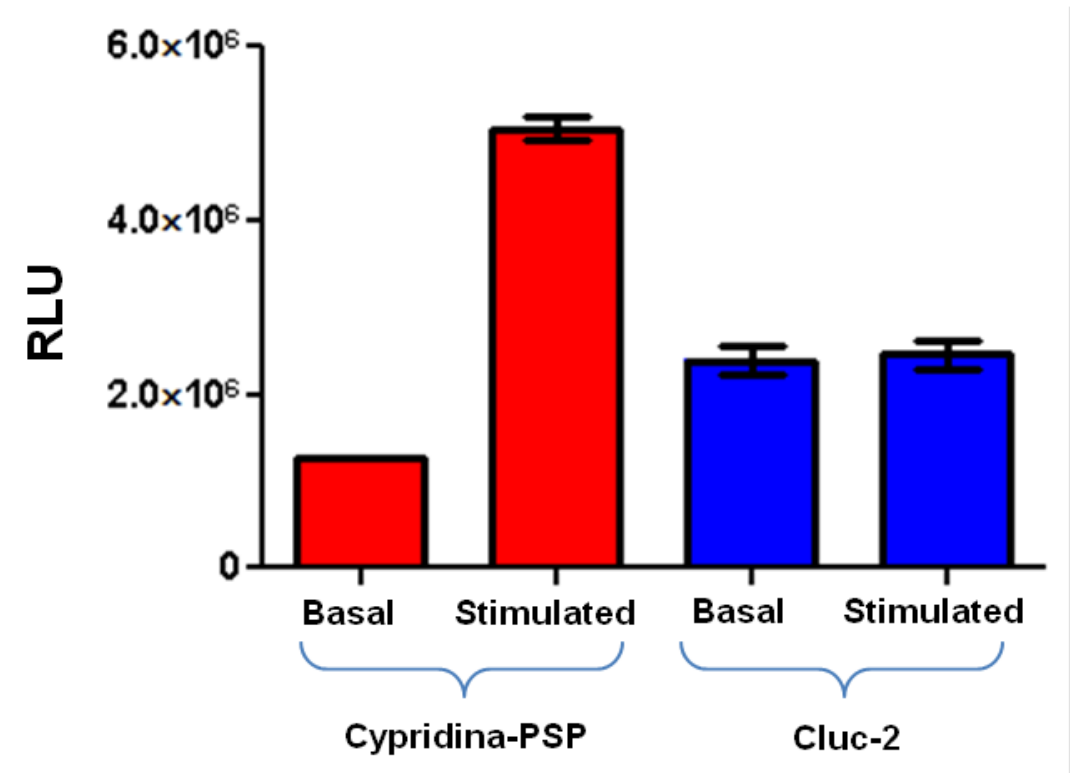

Figure 5: Theoretical transfection data of a comparison between the negative control Cluc-2 (blue), and the experimental variable Cyp-PSP (red). $(\mathrm{N}=3)$ In this hypothetical experiment, both the basal and stimulated results of the negative control have similar RLU values of 1.2 million. Conversely, the stimulated values for Cyp-PSP, five million, are much higher than the basal counterpart values, 1.2 million. 
Figure 6: Hypothetical Stimulated / Basal Ratio Data

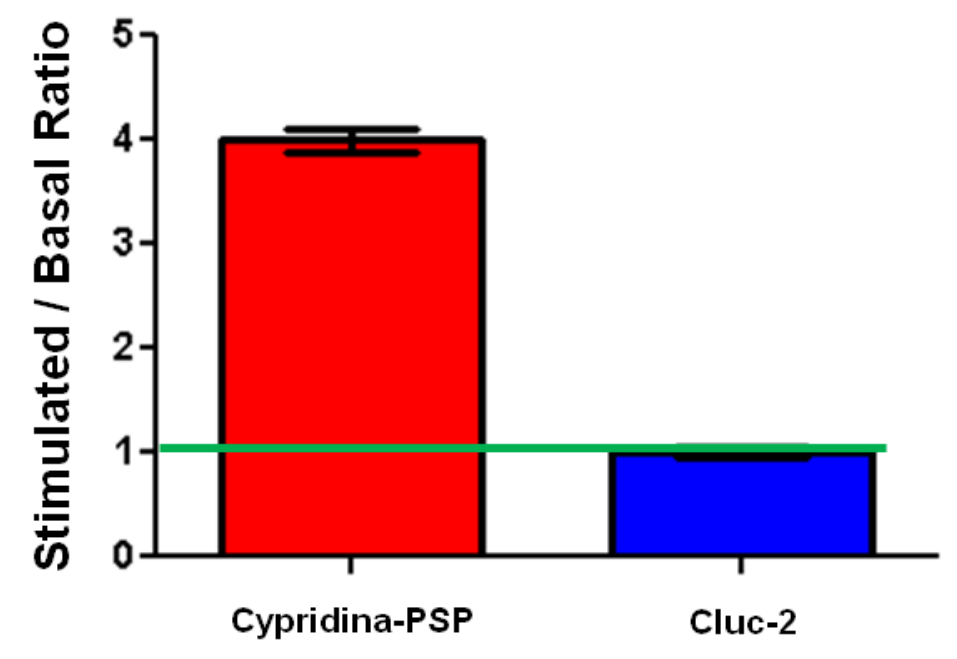

Figure 6: The stimulated RLU values were divided by their basal analogues, and the quotient is a ratio, which can help interpret the difference between basal and regulated secretion. Basal secretion is defined as a ratio of one. Stimulated secretion is operationally defined as any value higher than one. It is important to note that basal secretion is always occurring, even when stimulated secretion is observed. Cluc2 has a ratio of exactly one, suggesting only basal secretion is occurring. Cyp-PSP has a ratio of four, suggesting regulated secretion is observed, and basal secretion is still occurring at one. 


\section{Using Gaussia as a luciferase tag}

The goal of this series of experiments was to find a way to distinguish between basal and stimulated secretion. The hypothesis was the PSP-Gaussia would show stimulated secretion, while the negative control, the fusion protein of just the signal sequence of PSP and gaussia (SSp- $\Delta$ SSgaussia), would show no stimulated secretion, just basal secretion while stimulated.

Triplicate wells, each initially seeded with $45 \mathrm{k}$ ParC10 cells, were each transfected with $100 \mathrm{ng}$ of the fusion protein clone Gaussia-PSP. In the same manner, triplicate wells were each transfected with $300 \mathrm{ng}$ of the fusion protein Gaussia-PSP. Likewise, triplicate wells, each initially seeded with $45 \mathrm{k}$ ParC10 cells, were each transfected with $100 \mathrm{ng}$ of $\mathrm{SSp} \Delta \mathrm{SS}$-Gaussia, the negative control. A fourth set of triplicate wells, each initially seeded with $45 \mathrm{k}$ ParC10 cells, were each transfected with $300 \mathrm{ng}$ of SSp $\Delta$ SS-Gaussia. An additional, 20 ng of CLuc-2, the transfection efficiency measure, was transfected into each well. To maintain consistency, the filler DNA pBlueScript II KS (+) was used to bring the total amount of transfection DNA for each well to $500 \mathrm{ng}$. Lipofectamine ${ }^{\mathrm{TM}}$ 2000 (Invitrogen) was used as the lipid transfection reagent.

The transfection was performed with a series of washes and the basal and stimulated media were applied and collected after thirty minutes consecutively. An assay was performed by first loading $20 \mu \mathrm{L}$ of each media sample into $12 \mathrm{x}$ $75 \mathrm{~mm}$ borsociliate glass tubes in duplicate. Then, the gaussia and cypridina luciferase solvent, buffer, and substrate solutions were made and loaded into the luminometer. The assay was performed in a Berthold Lumat 9501 luminomter. 
The average of the three transfection experiments showed both basal and stimulated secretion are occurring for $300 \mathrm{ng}$ of SSp- $\Delta$ SSgaussia Figure 7. However, the average of $100 \mathrm{ng}$ of SSp- $\Delta$ SSgaussia is right at the green line and thus only basal secretion is occurring Figure 7.

The conclusion is SSp $\Delta$ SSgaussia, the negative control may show regulated secretion. Thus, it is a poor negative control. Additionally, Gaussia could be the protein with a sorting sequence directing the fusion protein into the regulated secretory pathway, and this would make it more difficult to discover the sorting sequence on the PSP protein, with the interference of Gaussia. It is important to note, while SSp $\Delta$ SSgaussia has the signal sequence of PSP on the $\mathrm{N}$-terminus, the signal sequence is cleaved by signal peptidase as the protein enters the endoplasmic reticulum (ER). Thus, the mature gaussia protein was showing potential stimulated secretion without the influence of PSP. An unbiased luciferase protein with the ability to be secreted is needed to form a new fusion protein. 
Figure 7: Gaussia-PSP Shows no Stimulated Secretion

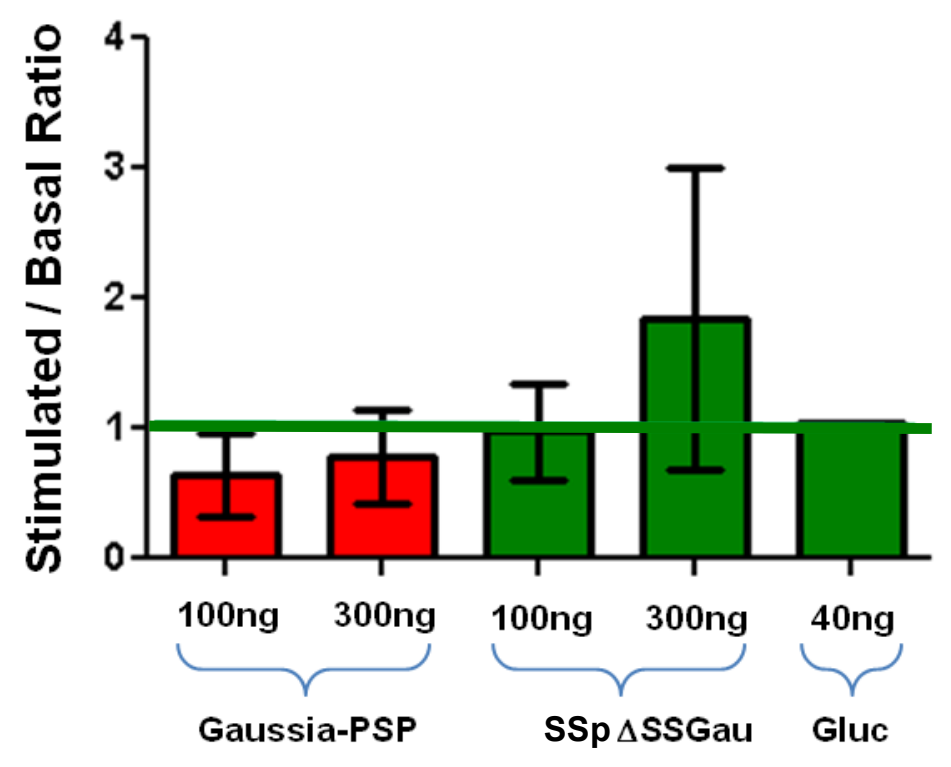

Figure 7: The graph above represents the average stimulated / basal ratio for three different secreted proteins, the corresponding genes being transfected into the cells. The bars represent an N of 1 to 3 . Gaussia-PSP showed no stimulated secretion for both the $100 \mathrm{ng}$ and $300 \mathrm{ng}$ transfected amounts. Likewise the 100 ng of gaussia with the PSP signal sequence attached did not show stimulated secretion either. The $300 \mathrm{ng}$ of SSp $\Delta$ SSgaussia showed variable but higher secretion, which may include some stimulated secretion, though the standard deviation was quite large. Lastly, the gaussia only showed no stimulated secretion. 


\section{Using Cypridina as a luciferase tag}

The transfection efficiency measure protein Cypridina did not show regulated secretion and therefore was used to make a new luciferase fusion protein with PSP Figures 4D, E, \& F. Cypridina was attached to PSP in two variants. The first variant was Cypridina attached to the C-terminus of PSP (PSPCypridina) Figure 4D and second, cypridina attached to the N-terminus of PSP without its signal sequence (Cypridina-PSP) Figure 4F. The two variations are necessary because one or the other might allow the protein to fold in a way to prevent the protein from entering the regulated secretory pathway. PSP from primary cells is not a fusion protein and the attached cypridina might affect the fold of PSP. Therefore, of the two versions synthesized, one of the recombinant proteins may be more efficient than the other in entering the regulated secretory pathway and will be more similar to the in-vivo PSP protein expressed in primary cells. Furthermore, the signal sequence of PSP was attached to the $\mathrm{N}$-terminus of Cypridina (SSp $\Delta S S C y p r i d i n a)$ as a negative control for future experiments Figure 4E.

The goal of the following series of experiments was to distinguish between basal and stimulated secretion using a fusion protein of PSP and Cypridina. The hypothesis was that cypridina-PSP fusion protein would enter the regulated secretory pathway while the control cypridina protein would not enter the pathway.

Triplicate wells, each initially seeded with $45 \mathrm{k}$ ParC10 cells growing in ParC5 media, were each transfected with $100 \mathrm{ng}$ or $300 \mathrm{ng}$ of the fusion protein 
Cypridina-PSP. Likewise, triplicate wells, were each transfected with $100 \mathrm{ng}$ or $300 \mathrm{ng}$ of PSP-Cypridina. A fifth set of triplicate wells, were each transfected with $300 \mathrm{ng}$ of PSP-Cypridina. Additionally, $50 \mathrm{ng}$ of CLuc-2, was transfected into triplicate wells. To maintain consistency, the filler DNA pBlueScript II KS (+) was used to bring the total amount of transfection DNA for each well to $500 \mathrm{ng}$. The Lipofectamine $^{\mathrm{TM}} 2000$ (Invitrogen) was used as the lipid transfection reagent.

The transfection was performed with a series of washes and the basal and stimulated medias were applied and collected after thirty minutes consecutively. An assay was performed by first loading $20 \mu \mathrm{L}$ of each media sample in duplicate onto a 96-well microplate. Then, the Cypridina luciferase solvent, buffer, and substrate solutions were made and loaded into the luminometer and the assay was run.

The 300 ng of Cypridina-PSP fusion protein, the Cypridina luciferase tag is on the N-terminus of PSP sans the signal sequence, showed some stimulated secretion (Figure 8). The $100 \mathrm{ng}$ of Cypridina-PSP and the $100 \mathrm{ng}$ and $300 \mathrm{ng}$ of PSP-Cypridina did not show stimulated secretion. In addition, in Figure 8, the 50 ng of Cluc-2, the negative control, did not show stimulated secretion either. Though an increase in Cyp-PSP was observed, an ANOVA test showed no significance. Since the Cypridina-PSP fusion protein seemed more efficient than PSP-Cypridina with a higher stimulated / basal ratio, it was then used for all future transfection experiments. Though $300 \mathrm{ng}$ of Cypridina-PSP showed some stimulated secretion, the standard error was still large, so the transfection 
efficiency was scrutinized and a change in the transfection reagent was made for the following transfection experiments.

In the previous transfection experiments, lipofectamine was used as a lipid transfection reagent. However, considering the high rate of cell mortality and low transfection efficiency of lipofectamine, a different lipid transfection reagent, FUGENE HD $®$ (Promega), was used for transfection \#13 and all transfections thereafter. The conditions were optimized, and for all transfections using FuGENE HD $®$ (Promega) the total amount of DNA was $200 \mathrm{ng}$ for each well. With the same goal of distinguishing between basal and stimulated secretion, another set of experiments was carried using FuGENE HD ${ }^{\circledR}$ (Promega) as the transfection reagent. The transfection setup was similar using $100 \mathrm{ng}$ of Cypridina-PSP and either $25 \mathrm{ng}$ or $2.5 \mathrm{ng}$ of Cluc-2 each transfected into one well of triplicate ParC10 cells. The harvest was carried out in an identical manner.

In Figure 9, the aggregation of transfections thirteen through nineteen show Cypridina-PSP with an average stimulated / basal ratio of 1.25. The average stimulated / basal ratio of $\mathrm{SSp} \Delta \mathrm{SS}-\mathrm{CLuc}-2$ was 1.05 . The aggregation of transfections fourteen through nineteen show Cypridina-PSP with an average stimulated / basal ratio of 1.2. Similarly, the average stimulated / basal ratio of $\mathrm{SSp} \Delta \mathrm{SS}-\mathrm{CLuc}-2$ was 1.0 . None of the averages were statistically significant based on a paired t-test which had a $p$-value of 0.12 with $\mathrm{N}=7$. The conclusion of this data is that no stimulated secretion is being observed for the Cypridina- 
PSP and likewise, no stimulated secretion is observed with the negative control $\operatorname{SSp} \Delta$ SScypridina. 
Figure 8: Cypridina-PSP and PSP-Cypridina Show No Stimulated Secretion

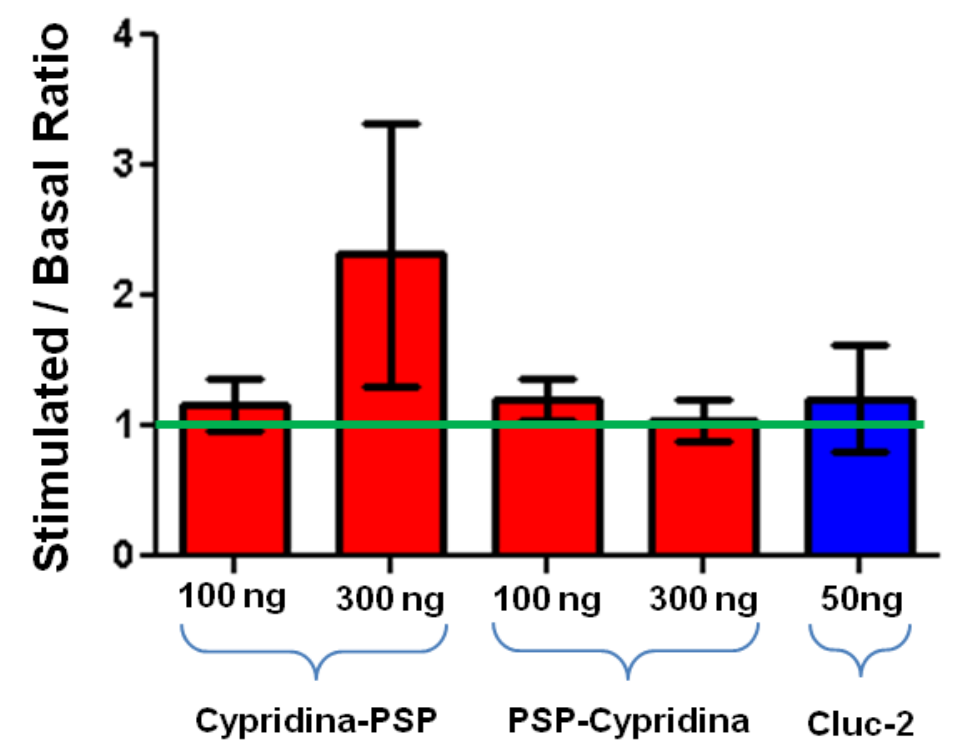

Figure 8: Regarding transfections 8, 9, \& 10, Cyp-PSP and PSP-Cyp displayed some regulated secretion when compared to the negative control Cluc-2. However, and ANOVA was performed and there was no significant difference. $\mathrm{N}=3, \mathrm{p}=0.4$ 
Figure 9: Cypridina-PSP Shows no Stimulated Secretion

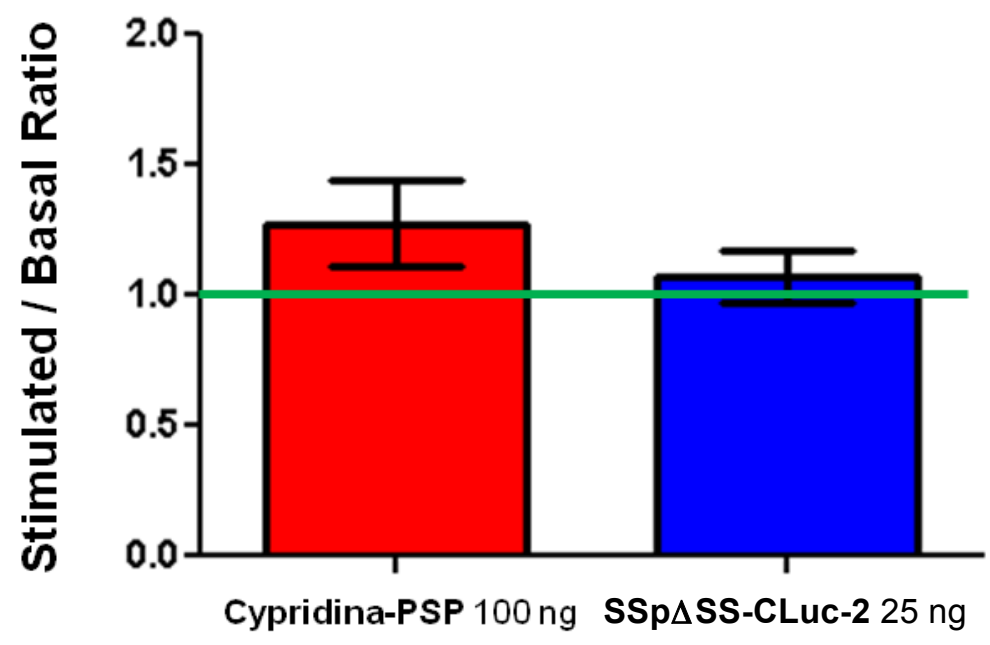

Figure 9: In transfections 13-19 Cyp-PSP was not significantly higher than the control, $25 \mathrm{ng}$ of SSp $\Delta$ SScyp, and no regulated secretion was observed. A paired t-test performed and there was no significant difference, $N=7, p=.12$ 


\section{Addition of Chromogranins to the transfection}

In the previous experiments, Cyp-PSP alone did not show regulated secretion and was never statistically significant from the controls, either Cypridina alone or SSp $\Delta$ SScyp. Since ParC10 cells are undifferentiated, the addition of some components present in primary cells might further differentiate the cells and bolster the regulated secretory pathway. It is known that chromogranins $\mathrm{A}$ and $\mathrm{B}$ are involved in the condensing of cargo proteins into granules and granule formation in primary rat parotid gland cells (Hosaka et al., 2004; Koshimizu, Cawley, Kim, Yergey, \& Loh, 2011). The goal of the following experiments was to add chromogranins to help secretory granulogenesis, granule formation, and thus increase the likelihood of seeing stimulated secretion (Inomoto et al., 2007; Koshimizu, et al., 2011; Koshimizu, Kim, Cawley, \& Loh, 2010). The hypothesis is that cells transfected with both Cypridina-PSP and chromogranin $\mathrm{B}(\mathrm{CgB})$ will show better stimulated secretion than cells transfected with just CLuc-2.

$100 \mathrm{ng}$ of the fusion protein Cypridina-PSP was transfected into ParC10 cells as described. $25 \mathrm{ng}$ of Cluc- 2 was transfected into ParC10 cells growing in triplicate wells. $100 \mathrm{ng}$ of Cypridina-PSP and $50 \mathrm{ng}$ of CgB were transfected into ParC10 cells growing in triplicate wells. 25 ng of Cluc- 2 and $\mathrm{CgB}$ were transfected into ParC10 cells. To maintain consistency, the filler DNA pBlueScript II KS (+) (Stratagene) was used to bring the total amount of transfection DNA for each well to $200 \mathrm{ng}$. FuGENE HD $\AA$ (Promega) was used as the lipid transfection reagent. 
Though the average stimulated / basal ratios of Cypridina-PSP with CgB were slightly above Cypridina-PSP by itself ( 1.5 and 1.25 respectively), the standard error was too great for any statistical significance (Figure 10). An ANOVA was performed and no statistical significance was observed based on a p-value higher than 0.05. Likewise, Cluc-2 and CgB together had a slightly higher stimulated / basal ratio than Cluc-2 alone (1.4 and 1.3 respectively), but there was no statistical significance (Figure 10). The conclusion from this set of data is Cyprdina-PSP transfected with $\mathrm{CgB}$ does not show more or any stimulated secretion than just Cypridina-PSP transfected alone. Also, Cluc-2, the negative control, worked accordingly when transfected with $\mathrm{CgB}$ and without $\mathrm{CgB}$. 
Figure 10: Chromogranin B Has No Significant Effect on Stimulated Secretion

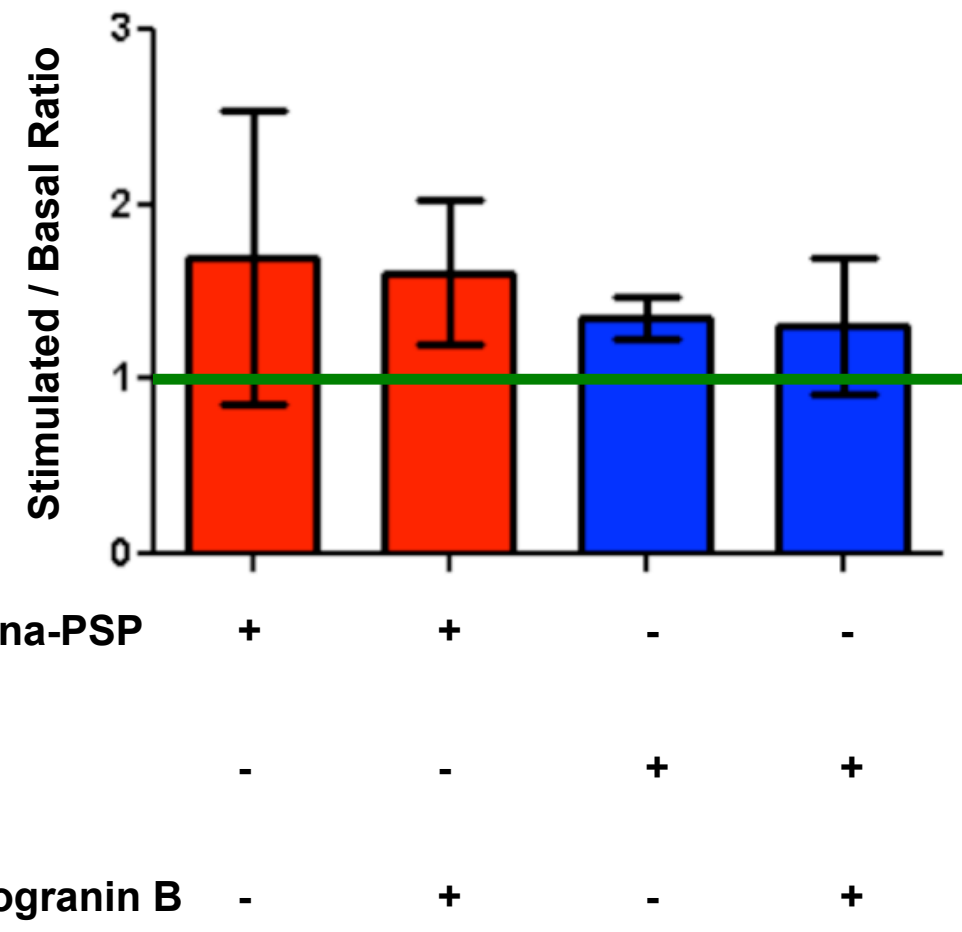

Figure 10: The above graph represents an average of the means of the stimulated / basal ratio of transfections $22,23, \& 24$. The average of CypridinaPSP with CgB was slightly higher than Cypridina-PSP without CgB, but the standard error was too large for any significant difference. Similarly, the average of Cluc-2 with $\mathrm{CgB}$ was slightly higher than $\mathrm{Cluc}-2$ without $\mathrm{CgB}$, but the standard error was too large for any significant difference. An ANOVA test confirmed there was no statistical significance between any of the bars with a p-value higher than 0.05 . 


\section{Using Forskolin as the Stimulant}

Considering the lack of regulated secretion observed in prior experiments, the isoproterenol could be insufficient for the observation of a robust secretion reaction. This thought was emphasized due to the use of trypsin $(0.25 \%)$ to passage and plate cells. Trypsin hydrolyses the outer cellular membrane proteins by cleaving arginine and lysine amino acid residues. The targeted proteins to be hydrolyzed are cell adhesion proteins, but trypsin also hydrolyses other proteins on the outer cell surface such as the beta-adrenergic receptors, which bind isoproterenol. Hence, in the past experiments, the possible lack of isoproterenol binding receptors may have prevented a significant and in vivo-like stimulation reaction. An alternative stimulant to isoproterenol is the stimulant forskolin, which activates the same cAMP pathway as isoproterenol, but does so intracellularly.

The transfection experiments were carried out in a similar manner as previous. Triplicate wells, each initially seeded with $45 \mathrm{k}$ ParC10 cells growing in ParC5 media, were each transfected with $100 \mathrm{ng}$ of the fusion protein CypridinaPSP. Likewise, triplicate wells, were each transfected with $25 \mathrm{ng}$ of Cluc-2. To maintain consistency, the filler DNA pBlueScript II KS (+) was used to bring the total amount of transfection DNA for each well to $200 \mathrm{ng}$. The FuGENE HD ${ }^{\circledR}$ (Promega) was used as the lipid transfection reagent.

The aggregate of transfections thirty through thirty-four showed the stimulated / basal ratio for Cyp-PSP to be 1.2 and Cluc-2 to be 1.1 (Figure 11). However, a t-test gave a p-value of 0.29 , thus there was no statistical 
significance between the two. Thus, no stimulated secretion was seen for either Cyp-PSP, or the negative control, Cluc-2. 
Figure 11: Forskolin Does Not Improve Stimulated Secretion

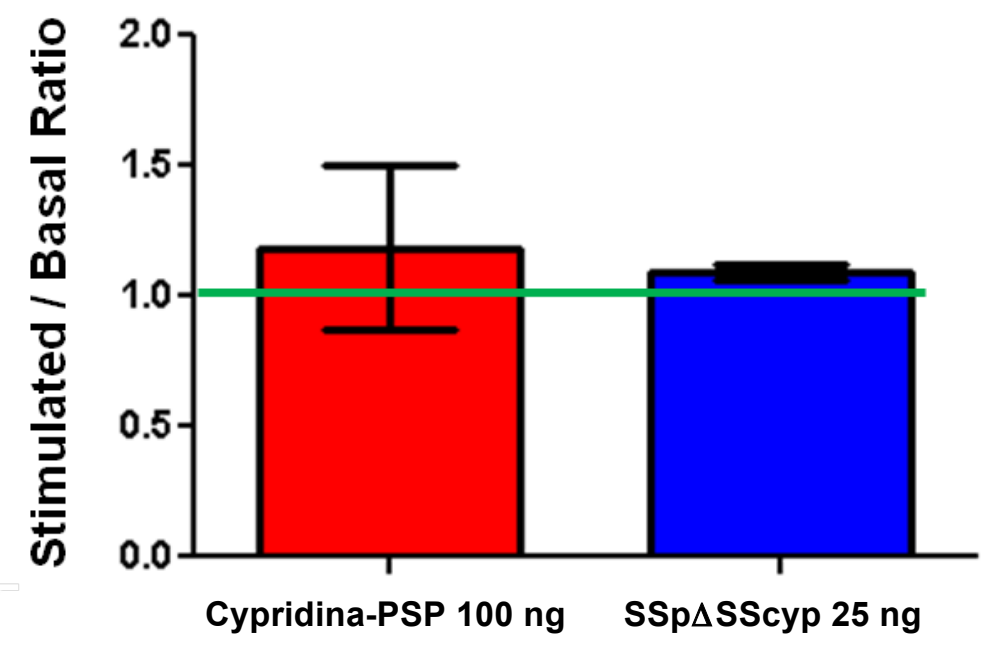

Figure 11: In transfections 30 - 34, Cyp-PSP did not demonstrate regulated secretion with an average stimulated / basal ratio of 1.2. Similarly, the negative control SSp $\Delta S$ Scyp did not demonstrate regulated secretion with an average stimulated / basal ratio of 1.1 . The data was analyzed using a t-test, $N=5, p=.29$ and thus the data was not statistically significant. 


\section{Stable Cell Lines}

The previous transient transfections showed little to no stimulated secretion and in many instances the negative control showed similar results to the experimental variable. Even with the addition of chromogranins, known for their role in dense core secretory granule formation, little to no stimulated secretion was observed. The cells used, ParC10 cells, are also known for lacking differentiation. Instead of performing more transient transfections, stable transfections might help the ParC10 cells to differentiate further by adding XBP and Mist1.

The vector used to create the stable cell lines is a cumate induced piggybac transposon system. Plasmid maps of the five clones inserted into the piggybac vector and used in stable cell creation are shown in Figure 12. The clones used for stable cell secretion experiments are listed in Table 2. The protein or proteins expressed in each line are listed in the fourth column of Table 2.

Stable cell lines were created to induce differentiation of the ParC10 cells. Stable cell lines also reduce the secretion experiment time because the cells already contain the recombinant DNA, which has been integrated into the cell's genome, as opposed to a transfected plasmid. Seven different cell lines were made using Cypridina-PSP, Cluc-2, transcription factors XBP and Mist1, and one empty or "vector only," negative control cell line Table 2. 
Figure 12: Plasmid Maps of the PiggyBac Clones for Stable Transfection

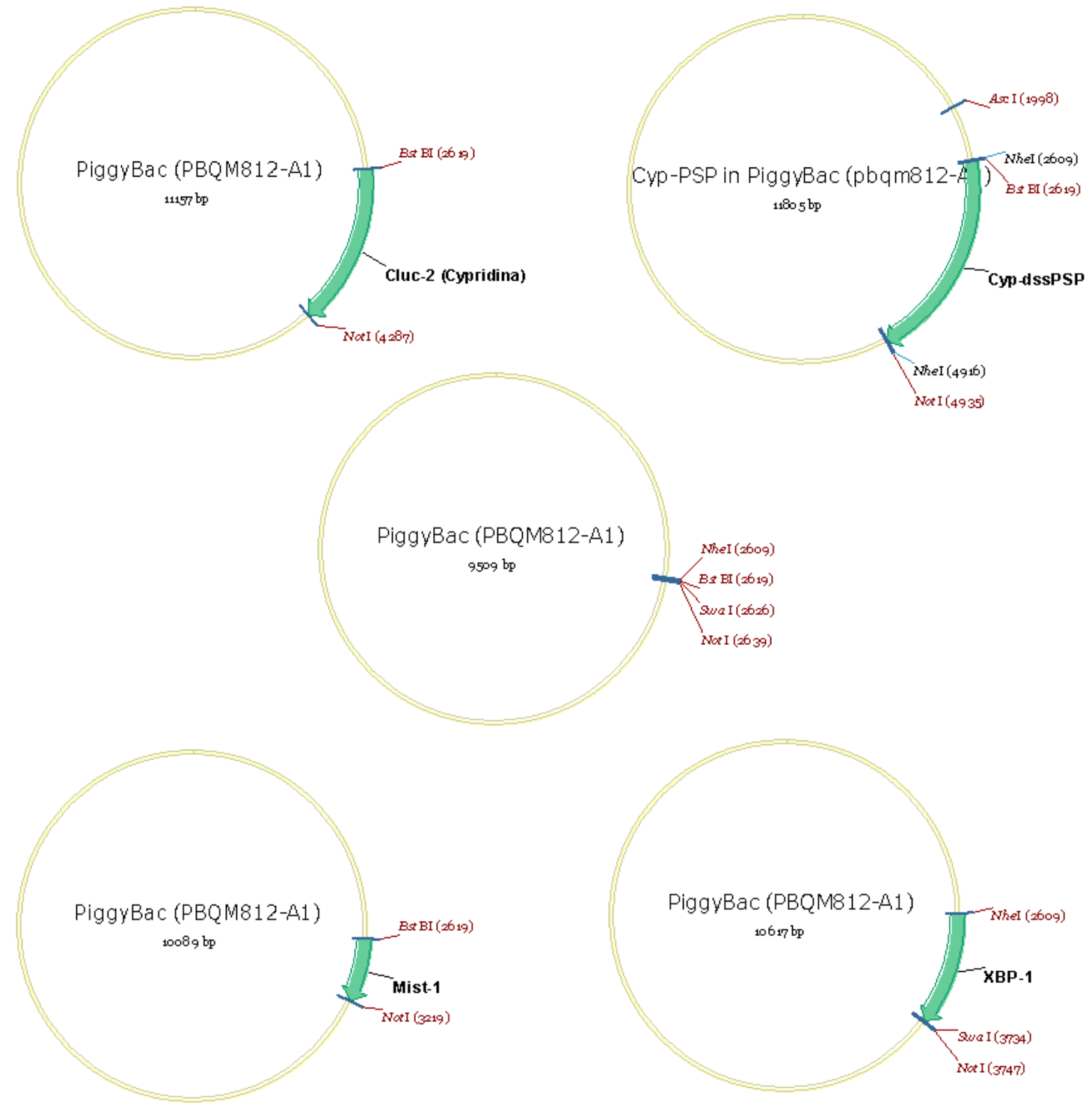

Figure 12: The Cyp-PSP, Cluc-2, Mist-1, and XBP cDNA fragments were cloned separately into PBQM812-A1 (PiggyBac Transponson System, SystemBio) vectors. 
Table 2:

Stable Cell Lines and the Genes they Contain

\begin{tabular}{|l|l|l|l|}
\hline Cell Line: & Mixed or Isolate & Transfected Genes: & Protein Name \\
\hline A & Mixed & Cyp-PSP & Cyp-PSP \\
\hline B & Mixed & Cyp-PSP & Cyp-PSP \\
\hline C & Mixed & Cypridina & CLuc-2 \\
\hline D & Mixed & Cyp-PSP, XBP, Mist1 & Cyp-PSP, XBP, Mist1 \\
\hline E & Mixed & Cyp-PSP, XBP, Mist1 & Cyp-PSP, XBP, Mist1 \\
\hline E $_{2}$ & Isolate & Cyp-PSP, XBP, Mist1 & Cyp-PSP, XBP, Mist1 \\
\hline F & Mixed & *empty vector & *no protein \\
\hline
\end{tabular}




\section{Stable Line Secretion Harvest, Cyp-PSP as experiment and Cypridina as Negative Control}

The goal of the following series of experiments was to observe stimulated secretion and distinguish it from basal secretion. The hypothesis is that stimulated secretion will be seen with the E2 cell line, and only basal secretion will be observed with the $\mathrm{C}$ cell line, the negative control.

The secretion experiment was setup similarly to the previous transient transfections, but the initial cell count was reduced to $30 \mathrm{k}$ cells per well. The cells were grown with regular ParC5 media for six hours, and then the media was changed to ParC5 media containing puromycin and cumate. The puromycin is to maintain only transposed cells, for the inserted cassette contains a puromycin resistance gene. The cumate is used to turn on the expression of the clone transposed into the genome. After the cells grew to $\sim 70 \%$ confluence, the secretion harvest was performed with a series of washes, and the basal and stimulated media was collected after thirty minutes consecutively. An assay was performed by loading $20 \mu \mathrm{L}$ of each media sample in duplicate into a 96-well microplate. Then, the cypridina luciferase solvent, buffer, and substrate solutions were made and loaded into the luminometer and the assay was run.

The E2 cell line showed an average stimulated / basal ratio of 1.4 and the C cell line (Cypridina only) showed an average stimulated / basal ratio of 1.25 Figure 13. An unpaired T-test of these two averages showed no significant differences. A different series of experiments was run using isoproterenol (30 $\mu \mathrm{M})$, forskolin $(10 \mu \mathrm{M})$, or both stimulants together (Figure 14). The average stimulated / basal ratios for the E2 cell line using IPR, Forskolin, or both was 2.4, 
2.0 , and 2.0 respectively. The average stimulated / basal ratios for the $C$ cell line using IPR, Forskolin, or both was $1.8,1.4$, and 1.3 respectively. After performing a two-tailed paired t-test between each pair of E2 and C cell lines stimulated similarly, no significant difference was found. 


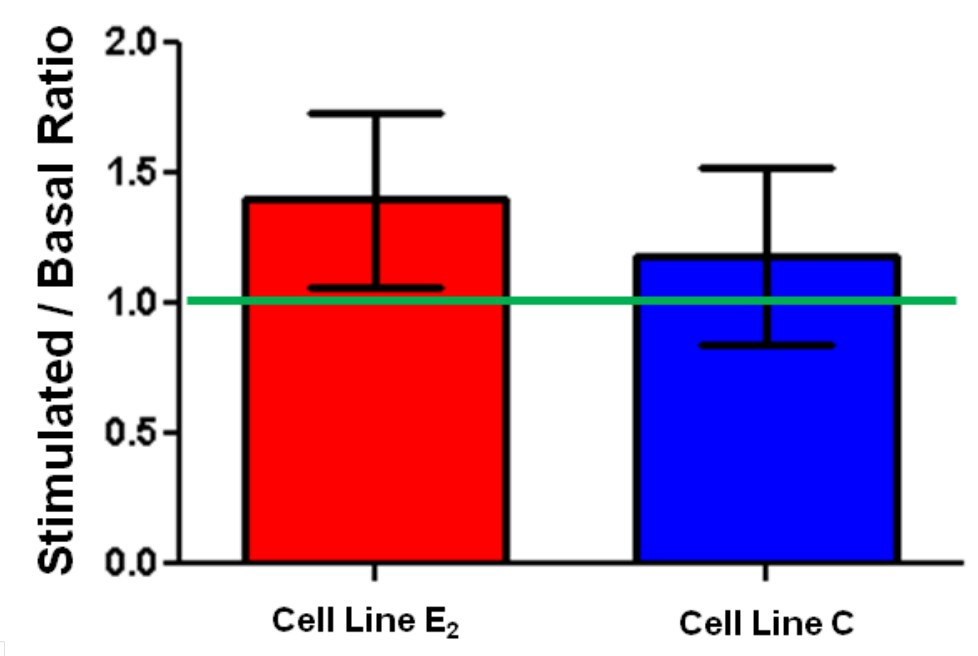

Figure 13: The graph above represents the average of the means of the stimulated / basal ratio of secretion experiments 17,18 , and 19 , using stable cell lines. Cell line $E_{2}$ did show an average ratio of 1.4, indicating stimulated secretion, but the standard error was too great for significance over the Cell line C control. A paired two-tailed t-test was performed and yielded a $p$ value less than .05 , but due to the variation among separate experiments, an unpaired t-test was used. The unpaired t-test yielded a $\mathrm{p}$ value of $0.67, \mathrm{~N}=3$. 
Figure 14: Comparison of Stimulants with Stable Cells
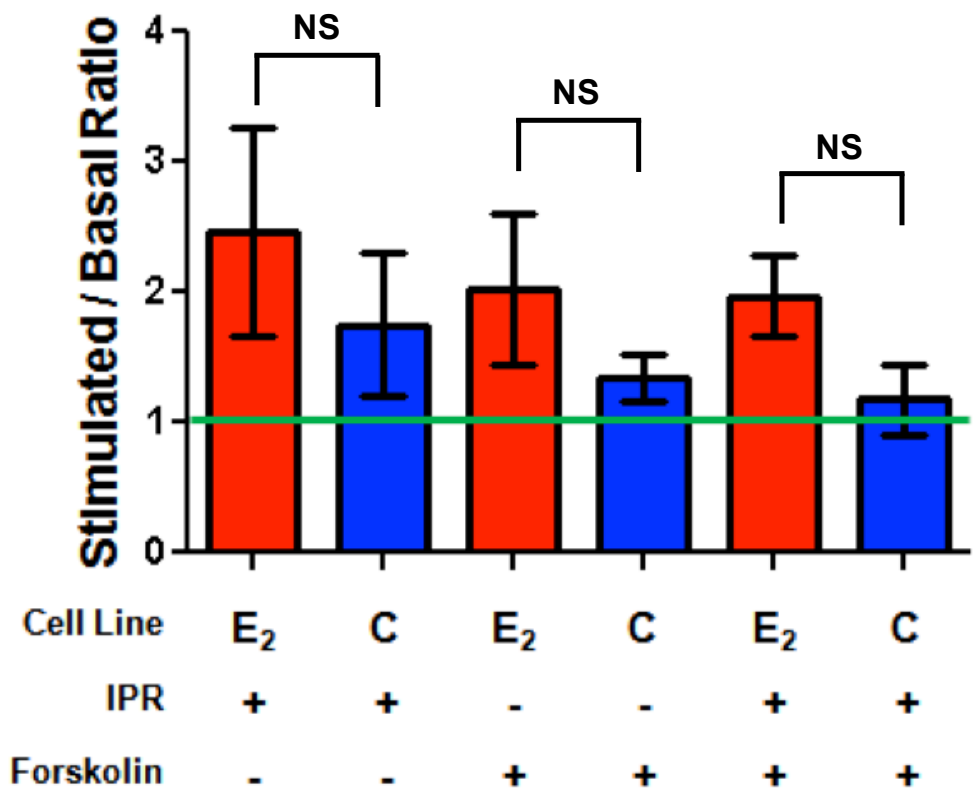

\section{Figure 14:}

The graph above represents the average of the means of the stimulated / basal ratio of secretion experiments $20,21,23, \& 25$, using stable cell lines. Cell line $E_{2}$ showed stimulated secretion with a stimulated / basal ratio of 2 or over for each stimulant setup of IPR alone, Forskolin alone, or a combination of both. However, cell line $\mathrm{C}$ also showed some stimulated secretion when either IPR or forskolin were used alone. Cell line $\mathrm{C}$ did not show stimulated secretion with the combination of both stimulants. Nevertheless, based on a two tailed paired t-test the differences between cell line $\mathrm{E}_{2}$ and its correspondingly stimulated control, cell line $C$, were never statistically significant, the $p$-value was more than 0.05 with an $\mathrm{N}$ or 3 or 4 . 


\section{Addition of XBP and Mist1 to help differentiate ParC10 cells}

Due to the lack of differentiation of immortalized ParC10 cells, the lack of normal expression of crucial proteins may be preventing the primary cell-like full function of the regulated secretory pathway. The expression of the transcription factor Mist1 is abated in ParC5 cells, when compared directly to primary rat parotid gland cells Figure 2. Thus, reintroducing XBP-1 and Mist1 to ParC10 cells may help make the regulated secretory pathway become more robust and facilitate regulated secretion of Cypridina-PSP. Using stable cell lines to reintroduce XBP-1 and Mist1 to ParC10 cells is important because the cells express these transcription factors for a longer period of time during a stable transfection secretion experiment than if transiently transfected.

The goal of this series of experiments was to determine if the presence of XBP and Mist1 transcription factors help increase stimulated secretion. The hypothesis was the D, E, and E2 cell lines show higher stimulated secretion than the $A$ and $B$ cell lines Table 2 .

The secretion experiment was setup with an initial cell count of $30 \mathrm{k}$ cells per well. The cells were grown with regular ParC5 media for six hours, and then the media was changed with ParC5 media containing puromycin and cumate. After the cells grew to $\sim 70 \%$ confluence, the secretion harvest was performed with a series of washes and the basal and stimulated medias were applied and collected after thirty minutes consecutively. An assay was performed by loading $20 \mu \mathrm{L}$ of each media sample in duplicated to a 96-well microplate. Then, the 
cypridina luciferase solvent, buffer, and substrate solutions were made and loaded into the luminometer and the assay was run.

In a comparison of secretion experiments $12,14,15$, and 18, Figure 15 cell lines $A$ and $B$ show a stimulated / basal ratio of 1.1 and 0.7 respectively. In the same series of experiments, cell lines D, E, and E2 show a stimulated / basal ratio of $0.7,0.5$, and 1.25 respectively. The control cell line $\mathrm{C}$, shows a ratio of 0.7. Though the E2 cell line shows some stimulated secretion, a 1 way ANOVA test was performed and no significance was observed with a p-value of 0.13. Additionally, an unpaired one-tail T-test was performed between the average for the A cell line and the E2 cell line and no significance was detected. 
FIGURE 15: Comparison of Stable Cell Line Stimulated / Basal Ratio

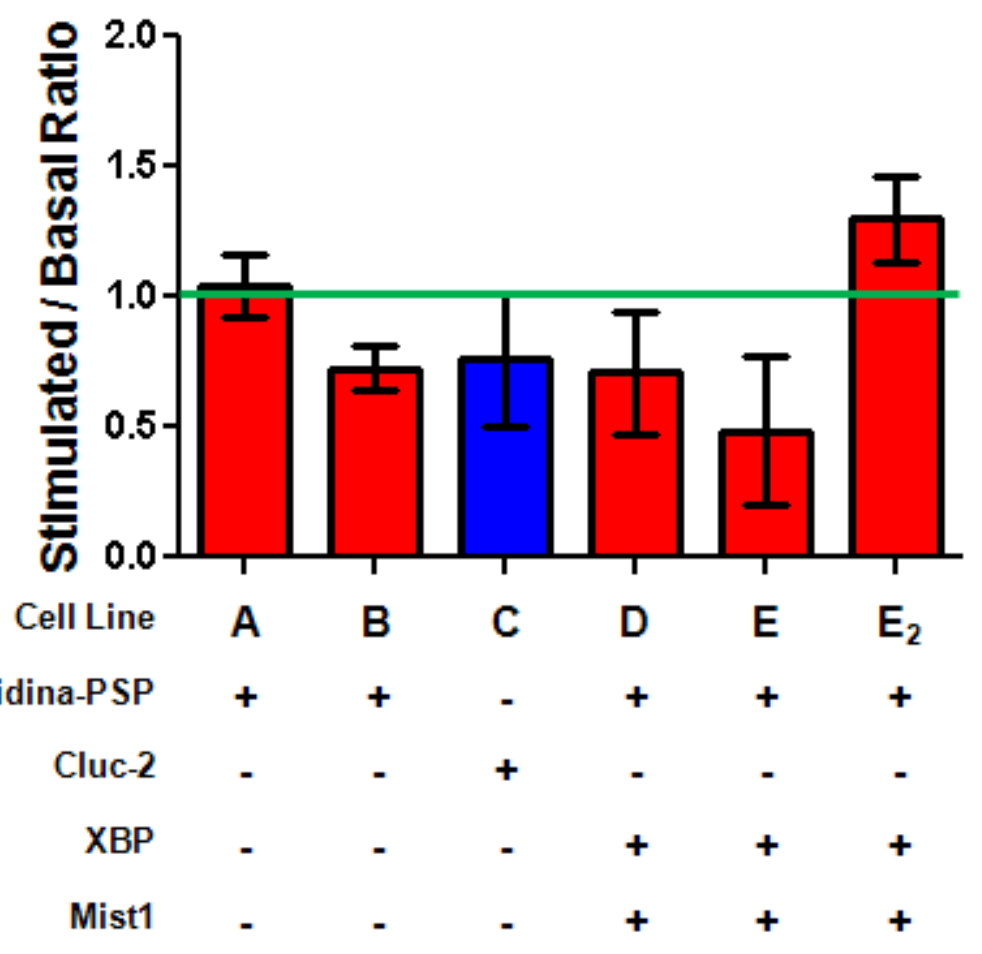

Figure 15: The graph above shows the average of the means of the stimulated / basal ratios of secretion experiments 12, 14, 15, and 18. An ANOVA was performed and none of the cell lines showed a significant difference from the control. The p-value was 0.13 and the $\mathrm{N}=4$. 


\section{Verification of the expression of XBP and Mist1 in the D, E, and E2 cell lines}

It can be determined that the piggybac vector successfully integrated both the puromycin resistant gene and the Cypridina-PSP gene into the genome of ParC10 cells because the cells grew in ParC5 media containing puromycin, and a Cypridina RLU signal was seen above background in all secretion experiments. However, XBP and Mist1 expression cannot be verified with an assay or simple growth means. Thus, the goal of this experiment was to verify the expression of XBP and Mist1 in the D, E, and E2 cell lines.

The A, C, D, E, and E2 cell lines were grown in T-25 flasks in ParC5 media containing puromycin and cumate. After reaching about $70 \%$ confluence, the media was aspirated and the cells were harvested with TRIzol reagent and RNA isolation was performed. Following the RNA isolation, rtPCR was performed with control groups not containing the reverse transcriptase enzyme. The product cDNA was then amplified using PCR supermix and primers for the XBP, Mist1, and Cyp-PSP plasmids separately. After amplification, loading dye was added and the samples were loaded onto a $1 \%$ agarose gel with $1 \mathrm{~kb}$ DNA ladder for molecular weight reference. The gel was run at 140 volts for 45 minutes.

Figure 16 shows the $1 \%$ agarose gel containing $1 \mathrm{~kb}+$ DNA ladder, amplified cDNA, synthesized from RNA from cell lines A, D, and E2. The columns for cell line A show no presence of XBP or Mist1 and the negative control columns, reverse transcriptase enzyme was not added to the control, for cell line A show no amplification of genomic DNA. The columns for cell line D show the presence of XBP while the negative controls show no cDNA presence. 
Lastly, the columns for cell line $E_{2}$ show the presence of XBP, yet the negative controls show no amplification.

The conclusion is cell lines $D$ and $E_{2}$ do show expression of XBP RNA, as they should because XBP was transfected into these particular cell lines Table 2. Yet, cell line A does not show XBP RNA expression, as XBP was not transfected into this line Table 2. Nevertheless, cells lines $D$ and $E_{2}$ do not show higher stimulated secretion than cell line A Figure 15 , even though $D$ and $E_{2}$ contain $\mathrm{XBP}$, which is known to promote biogenesis of regulated secretory pathway components. 
Figure 16: Gel Electrophoresis: Cell lines $D$ and $E_{2}$ Express XBP-1 Cell Line A

Cell Line D

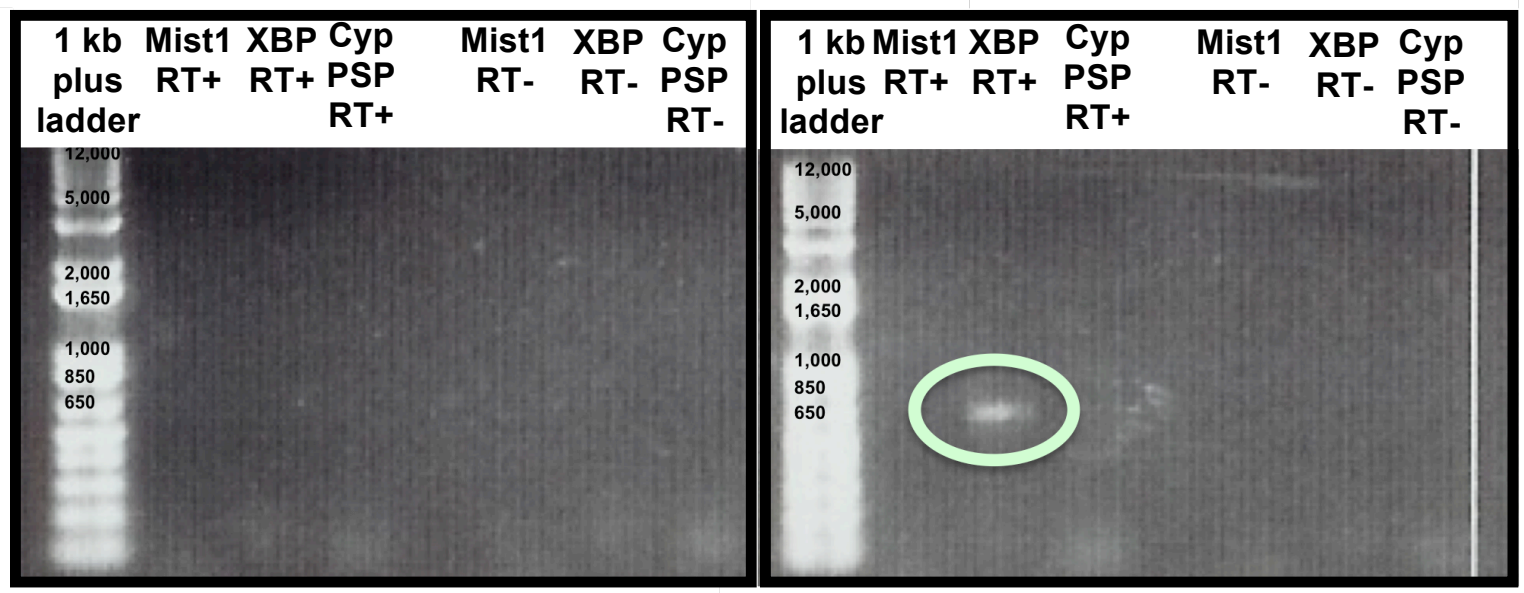

Cell Line $\mathrm{E}_{2}$

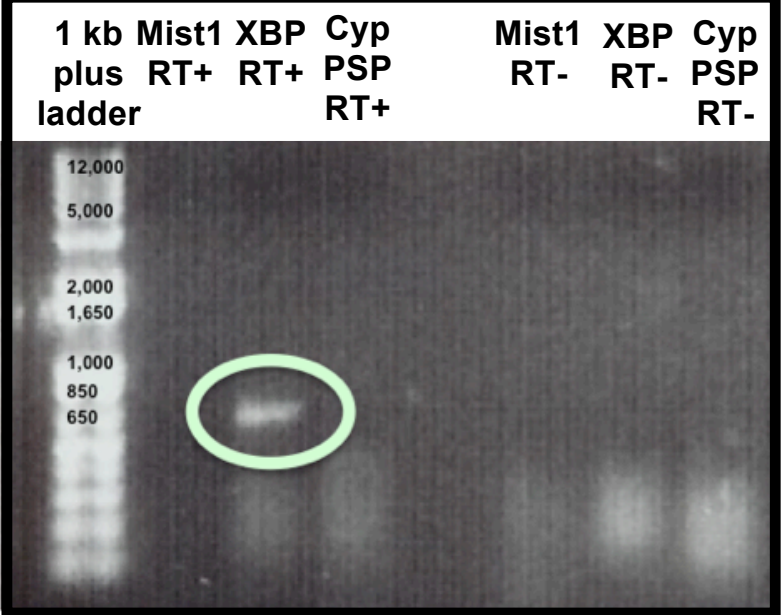

Figure 16: The pictures above are from a 1\% agarose gel. RNA was extracted from cell lines $A, D$, and $E_{2}$, converted to cDNA and the specific transcription factors Mist1, XBP, and Cyp-PSP were amplified. XBP is $\sim 650 \mathrm{bp}$. Cell line A shows no XBP expression, as it should. Cell lines $D$ and $E_{2}$ show XBP expression. 


\section{Discussion}

To date, the mechanism for how cargo proteins enter the regulated secretory pathway is unknown. Discovering the mechanism of "protein trafficking" would benefit both the scientific and medical communities because the regulated secretory pathway is found in all major exocrine cell types. Clinically eminent conditions such as diabetes and xerostomia are directly associated with these cell types that maintain the regulated secretory pathway. Additionally, a greater understanding of protein trafficking could make therapeutic models more reliable.

Current literature describes various secretory pathways in exocrine cells; two focal pathways for this paper being the constitutive and regulated secretory pathways. Our experimental model attempts to distinguish between these two pathways with the understanding the constitutive pathway never turns off, even when stimulated. Conversely, the regulated secretory pathway only turns on in the presence of a stimulus. With this knowledge, we designed the secretion experiments so we could measure both the constitutive secretion and the stimulated secretion and then compare the two.

Equally important to our experimental model is the observation that PSP is only found in the saliva and not the blood, suggesting it only enters the apical regulated secretory pathway (Darling, 2012; Venkatesh, et al., 2007). While PSP is only found in saliva, other prominent salivary proteins such as amylase are found in both the saliva and blood, suggesting PSP is unique and this 
characteristic is advantageous for our study. These findings were the result of a western blot analysis of rat serum; traces of amylase were found but PSP was not(Darling, 2012; Venkatesh, et al., 2007). With a luciferase protein attached to PSP, it would be only the PSP portion of the fusion protein signaling for entrance into the regulated secretory pathway. Our original question was which part of the PSP protein is responsible for signaling the regulated secretory pathway.

In the beginning of this research, luciferase protein Gaussia may have been directing the Gaussia-PSP fusion protein into the stimulated pathway on its own accord. It is possible that Gaussia has a sorting sequence directing itself into the regulated secretory pathway. To continue using Gaussia as the luciferase protein fused to PSP would be bias. In other words, if stimulated secretion was seen with Gaussia-PSP, we would not know if it was the PSP portion of the fusion protein directing itself into the stimulated pathway, or if it was the Gaussia portion directing the fusion protein into the pathway. Consequently, we switched the fusion luciferase protein to cypridina, which had previously not shown any stimulated secretion.

Unlike Gaussia, Cypridina alone, (Cluc-2), did not show any stimulated secretion, so it proved to be a good negative control. The experiments following the switch to using Cypridina as the luciferase fused to PSP showed no significant stimulated secretion. So, with a good negative control, effort was made to push the use of Cypridina-PSP and Cluc-2 forward as the primary independent variables. The following experiments used Cypridina-PSP and Cluc- 
2, but had additional factors either added or changed to promote the secretion of the cell in some way.

Chromoganin $\mathrm{B}(\mathrm{CgB})$, known for its role in dense secretory core granule (DCSG) formation was added the transfection with Cypridina-PSP (Koshimizu, et al., 2011). It was thought CgB would help increase DCSG formation and thus allow more Cypridina-PSP to enter and be stored in the DCSGs. The current literature shows chromogranins added to cells increases DCSG biogenesis. By adding Chromogranin B, a greater amount of Cypridina-PSP would be stored. Thus, after stimulus treatment, more Cypridina-PSP would be released and more stimulated secretion would be observed. Our results showed CgB did not increase stimulated secretion of Cypridina-PSP, nor did it increase the stimulated secretion of Cluc-2. Similarly, in the current literature there is evidence that expression of Chromogranin A, known for its involvement in DCSG synthesis, could not restore the regulated secretory pathway in PC12-27 cells (Kim, et al., 2006; Malosio, Giordano, Laslop, \& Meldolesi, 2004).

Isoproterenol, the neurotransmitter epinephrine agonist used to stimulate the ParC10 cells, binds to $\beta$-adrenergic receptors on the cell surface. During passaging of the cells, trypsin is used, and it was thought the trypsin might digest the surface receptors. Forskolin, a $\beta$-adrenergic agonist that turns on the stimulated pathway intracellularly, was used instead of isoproterenol to bypass the possible lack of receptors on the cell surface. The hypothesis was the use of forskolin, as a stimulant, would allow Cypridina-PSP to show stimulated secretion. The results from the experiments using forskolin were negative and 
Cypridina-PSP showed no stimulated secretion. At this point, the focus turned more to the ParC10 cells and their lack of differentiation.

For the next set of experiments, we followed the same model of transfecting Cypridina-PSP into ParC10 cells, but instead of performing transient transfections, we performed stable transfections. By integrating the CypridinaPSP, XBP-1, and Mist1 genes into the genome of the ParC10 cells, they have the potential to induce some differentiation of the cells. Using stable cells was crucial because XBP-1 and Mist1 needed time to express and help facilitate the differentiation of the cells. The time frame for a transcription factors to act on and regulate differentiation factors is too short during transient transfections, but long enough during stably transfected cell secretion experiments. Additionally, the transfection efficiency is increased greatly because theoretically, only the stably transfected cells live since there is a puromycin resistance gene in the vector, and the antibiotic is added to the cell media.

The hypothesis was that Cypridina-PSP would show stimulated secretion in the cell lines it where it was expressed, cell lines $A, B, D, E$, and $E_{2}$. The results from the stable transfection secretion experiments did not show significant Cypridina-PSP stimulated secretion. The negative control, cell line C, did not show stimulated secretion.

The stable cell lines created included cell lines with transcription factors thought to have important roles in differentiation of exocrine cells (Lee, et al., 2005; Tian, et al., 2010). These transcription factors are XBP and Mist1. Both were included in cell lines $D$ and $E$ and consequently were included in the 
isolated cell line $E_{2}$. The $E_{2}$ cell line is isolated because it was developed from a single colony of the E cells, thus each individual cell should have genes XBP-1, Mist1, and Cyp-PSP integrated in the same location on the chromosomes. Since XBP-1 and Mist1 are transcription factors found in primary rat parotid gland cells, their presence should help differentiate the cells in which they are expressed. More importantly, these factors are associated with PSP gene expression, so they should help bolster the regulated secretory pathway that PSP normally enters in primary cells.

The hypothesis for the secretion experiments $12,14,15$, and 18 was the cell lines expressing Cypridina-PSP, XBP, and Mist1 (cell lines D, E, and $E_{2}$ ) would show better stimulated secretion than the cell lines expressing just Cypridina-PSP (cell lines A and B). The results did not show any significant difference between the cell lines with just Cypridina-PSP and the cell lines with Cypridina-PSP, XBP, and Mist1. The conclusion from this set of experiments is that these additional transcription factors do not help augment the regulated secretory pathway to the level where constitutive and stimulated secretion pathways are distinguishable.

The overall conclusion to be drawn from all of the experiments performed for this research paper is that the ParC10 cells lack a robust regulated secretory pathway. Even with the addition of transcription factors and proteins known for their involvement in the regulated secretory process, the level of differentiation is too far removed from primary cells and their respective processes. An 
immortalized parotid cell line carrying many more transcription factors and primary cellular processes is needed. 


\section{REFERENCES}

Abdolhosseini, M., Sotsky, J. B., Shelar, A. P., Joyce, P. B., \& Gorr, S. U. (2012). Human parotid secretory protein is a lipopolysaccharide-binding protein: identification of an anti-inflammatory peptide domain. Molecular and Cellular Biochemistry, 359(1-2), 1-8.

Arvan, P., \& Castle, J. D. (1986). Isolated secretion granules from parotid glands of chronically stimulated rats possess an alkaline internal $\mathrm{pH}$ and inwarddirected H+ pump activity. The Journal of Cell Biology, 103(4), 1257-1267.

Badr, C. E., Hewett, J. W., Breakefield, X. O., \& Tannous, B. A. (2007). A highly sensitive assay for monitoring the secretory pathway and ER stress. PloS one, 2(6), e571.

Baker, O. J. (2010). Tight junctions in salivary epithelium. Journal of Biomedicine \& Biotechnology, 2010, 278948.

Baker, O. J., Camden, J. M., Redman, R. S., Jones, J. E., Seye, C. I., Erb, L., et al. (2008). Proinflammatory cytokines tumor necrosis factor-alpha and interferon-gamma alter tight junction structure and function in the rat parotid gland Par-C10 cell line. American Journal of Physiology. Cell Physiology, 295(5), C1191-1201.

Baker, O. J., Schulz, D. J., Camden, J. M., Liao, Z., Peterson, T. S., Seye, C. I., et al. (2010). Rat parotid gland cell differentiation in three-dimensional culture. Tissue engineering. Part C, Methods, 16(5), 1135-1144.

Bhalla, S., Tandon, S., \& Satyamoorthy, K. (2010). Salivary proteins and early childhood caries: A gel electrophoretic analysis. Contemporary Clinical Dentistry, 1(1), 17-22.

Bingle, L., \& Bingle, C. D. (2011). Distribution of human PLUNC/BPI foldcontaining (BPIF) proteins. Biochemical Society Transactions, 39(4), 1023-1027.

Borgonovo, B., Ouwendijk, J., \& Solimena, M. (2006). Biogenesis of secretory granules. Current Opinion in Cell Biology, 18(4), 365-370. 
Cabras, T., lavarone, F., Pirolli, D., Cristina De Rosa, M., Vitali, A., Faa, G., et al. (2013). Top-down HPLC-ESI-MS characterization of rat gliadoralin A, a new member of the family of rat submandibular gland glutamine-rich proteins and potential substrate of transglutaminase. Journal of Separation Science.

Castle, A. M., Huang, A. Y., \& Castle, J. D. (2002). The minor regulated pathway, a rapid component of salivary secretion, may provide docking/fusion sites for granule exocytosis at the apical surface of acinar cells. Journal of Cell Science, 115(Pt 14), 2963-2973.

Chan, Y. H., Huang, T. W., Young, T. H., \& Lou, P. J. (2011). Human salivary gland acinar cells spontaneously form three-dimensional structures and change the protein expression patterns. Journal of Cellular Physiology, 226(11), 3076-3085.

Courel, M., Soler-Jover, A., Rodriguez-Flores, J. L., Mahata, S. K., Elias, S., Montero-Hadjadje, M., et al. (2010). Pro-hormone secretogranin II regulates dense core secretory granule biogenesis in catecholaminergic cells. The Journal of Biological Chemistry, 285(13), 10030-10043.

Darling, D. S., Venkatesh, S.G, Goyal, D, Carenbauer, \& A.L. (2012). "Phosphatidylinositol Bisphosphate Mediated Sorting of Secretory Granule Cargo". In R. Weigert (Ed.), Crosstalk and Integration of Membrane Trafficking Pathways: InTech.

Denny, P., Hagen, F. K., Hardt, M., Liao, L., Yan, W., Arellanno, M., et al. (2008). The proteomes of human parotid and submandibular/sublingual gland salivas collected as the ductal secretions. Journal of Proteome Research, 7(5), 1994-2006.

Dikeakos, J. D., \& Reudelhuber, T. L. (2007). Sending proteins to dense core secretory granules: still a lot to sort out. The Journal of Cell Biology, 177(2), 191-196.

Folsch, H., Mattila, P. E., \& Weisz, O. A. (2009). Taking the scenic route: biosynthetic traffic to the plasma membrane in polarized epithelial cells. Traffic, 10(8), 972-981. 
Geetha, C., Venkatesh, S. G., Bingle, L., Bingle, C. D., \& Gorr, S. U. (2005). Design and validation of anti-inflammatory peptides from human parotid secretory protein. Journal of Dental Research, 84(2), 149-153.

Geetha, C., Venkatesh, S. G., Dunn, B. H., \& Gorr, S. U. (2003). Expression and anti-bacterial activity of human parotid secretory protein (PSP).Biochemical Society Transactions, 31(Pt 4), 815-818.

Gervasio, A., D'Orta, G., Mujahed, I., \& Biasio, A. (2011). Sonographic anatomy of the neck: The suprahyoid region. Journal of Ultrasound, 14(3), 130-135.

Gorr, S. U., Venkatesh, S. G., \& Darling, D. S. (2005). Parotid secretory granules: crossroads of secretory pathways and protein storage. Journal of Dental Research, 84(6), 500-509.

Hadley, T., Song, C., Wells, L., Lehnhardt, J., Rogers, M. W., Anderson, J., et al. (2013). Does hyperbaric oxygen therapy have the potential to improve salivary gland function in irradiated head and neck cancer patients? Medical Gas Research, 3(1), 15.

Helmerhorst, E. J., \& Oppenheim, F. G. (2007). Saliva: a dynamic proteome. Journal of Dental Research, 86(8), 680-693.

Heo, S. M., Choi, K. S., Kazim, L. A., Reddy, M. S., Haase, E. M., Scannapieco, F. A., et al. (2013). Host defense proteins derived from human saliva bind to Staphylococcus aureus. Infection and Immunity, 81(4), 1364-1373.

Ho, K., Lin, H., Ann, D. K., Chu, P. G., \& Yen, Y. (2011). An overview of the rare parotid gland cancer. Head \& Neck Oncology, 3, 40.

Hosaka, M., Suda, M., Sakai, Y., Izumi, T., Watanabe, T., \& Takeuchi, T. (2004). Secretogranin III binds to cholesterol in the secretory granule membrane as an adapter for chromogranin A. The Journal of Biological Chemistry, 279(5), 3627-3634.

Huang, A. Y., Castle, A. M., Hinton, B. T., \& Castle, J. D. (2001). Resting (basal) secretion of proteins is provided by the minor regulated and constitutivelike pathways and not granule exocytosis in parotid acinar cells. The Journal of Biological Chemistry, 276(25), 22296-22306. 
Humphrey, S. P., \& Williamson, R. T. (2001). A review of saliva: normal composition, flow, and function. The Journal of Prosthetic Dentistry, 85(2), 162-169.

Inomoto, C., Umemura, S., Egashira, N., Minematsu, T., Takekoshi, S., Itoh, Y., et al. (2007). Granulogenesis in non-neuroendocrine COS-7 cells induced by EGFP-tagged chromogranin A gene transfection: identical and distinct distribution of $\mathrm{CgA}$ and EGFP. The Journal of Histochemistry and Cytochemistry : Official Journal of the Histochemistry Society, 55(5), 487493.

Kim, T., Gondre-Lewis, M. C., Arnaoutova, I., \& Loh, Y. P. (2006). Dense-core secretory granule biogenesis. Physiology, 21, 124-133.

Koshimizu, H., Cawley, N. X., Kim, T., Yergey, A. L., \& Loh, Y. P. (2011). Serpinin: a novel chromogranin A-derived, secreted peptide up-regulates protease nexin-1 expression and granule biogenesis in endocrine cells. Molecular Endocrinology, 25(5), 732-744.

Koshimizu, H., Kim, T., Cawley, N. X., \& Loh, Y. P. (2010). Reprint of: Chromogranin A: a new proposal for trafficking, processing and induction of granule biogenesis. Regulatory Peptides, 165(1), 95-101.

Lee, A. H., Chu, G. C., Iwakoshi, N. N., \& Glimcher, L. H. (2005). XBP-1 is required for biogenesis of cellular secretory machinery of exocrine glands. The EMBO Journal, 24(24), 4368-4380.

Li, C., Li, Y., Zhang, D., Yang, Z., \& Wu, L. (2012). 3D-FIESTA MRI at 3 T demonstrating branches of the intraparotid facial nerve, parotid ducts and relation with benign parotid tumours. Clinical Radiology, 67(11), 10781082.

Lord, C., Bhandari, D., Menon, S., Ghassemian, M., Nycz, D., Hay, J., et al. (2011). Sequential interactions with Sec23 control the direction of vesicle traffic. Nature, 473(7346), 181-186.

Malosio, M. L., Giordano, T., Laslop, A., \& Meldolesi, J. (2004). Dense-core granules: a specific hallmark of the neuronal/neurosecretory cell phenotype. Journal of Cell Science, 117(Pt 5), 743-749. 
Mills, S. E. (2007). Histology for Pathologists (3rd Edition ed.). Philadelphia: Lippcott Williams \& Wilkins.

Nakajima, Y., Kobayashi, K., Yamagishi, K., Enomoto, T., \& Ohmiya, Y. (2004). cDNA cloning and characterization of a secreted luciferase from the luminous Japanese ostracod, Cypridina noctiluca. Bioscience, Biotechnology, and Biochemistry, 68(3), 565-570.

Nelson, J., Manzella, K., \& Baker, O. (2013). Current cell models for bioengineering a salivary gland: a mini-review of emerging technologies. Oral Diseases, 19(3), 236-244.

Perez, P., Rowzee, A. M., Zheng, C., Adriaansen, J., \& Baum, B. J. (2010). Salivary epithelial cells: an unassuming target site for gene therapeutics. The International Journal of Biochemistry \& Cell Biology, 42(6), 773-777.

Quissell, D. O., Turner, J. T., \& Redman, R. S. (1998). Development and characterization of immortalized rat parotid and submandibular acinar cell lines. European Journal of Morphology, 36 Suppl, 50-54.

Rudney, J. D. (1995). Does variability in salivary protein concentrations influence oral microbial ecology and oral health? Critical reviews in oral biology and medicine : an official publication of the American Association of Oral Biologists, 6(4), 343-367.

Shetty, S. R., Bhowmick, S., Castelino, R., \& Babu, S. (2012). Drug induced xerostomia in elderly individuals: An institutional study. Contemporary Clinical Dentistry, 3(2), 173-175.

Ship, J. A., Pillemer, S. R., \& Baum, B. J. (2002). Xerostomia and the geriatric patient. Journal of the American Geriatrics Society, 50(3), 535-543.

Sobota, J. A., Ferraro, F., Back, N., Eipper, B. A., \& Mains, R. E. (2006). Not all secretory granules are created equal: Partitioning of soluble content proteins. Molecular Biology of the Cell, 17(12), 5038-5052.

Soltoff, S. P., \& Hedden, L. (2010). Isoproterenol and cAMP block ERK phosphorylation and enhance [Ca2+]i increases and oxygen consumption by muscarinic receptor stimulation in rat parotid and submandibular acinar cells. The Journal of Biological Chemistry, 285(18), 13337-13348. 
Su, Y. X., Benedek, G. A., Sieg, P., Liao, G. Q., Dendorfer, A., Meller, B., et al. (2013). Radioprotective effect of lidocaine on neurotransmitter agonistinduced secretion in irradiated salivary glands. PloS one, 8(3), e60256.

Takuma, T., Shitara, A., Arakawa, T., Okayama, M., Mizoguchi, I., \& Tajima, Y. (2013). Isoproterenol stimulates transient SNAP23-VAMP2 interaction in rat parotid glands. FEBS letters, 587(6), 583-589.

Tian, X., Jin, R. U., Bredemeyer, A. J., Oates, E. J., Blazewska, K. M., McKenna, C. E., et al. (2010). RAB26 and RAB3D are direct transcriptional targets of MIST1 that regulate exocrine granule maturation. Molecular and Cellular Biology, 30(5), 1269-1284.

Tran, S. D., Liu, Y., Xia, D., Maria, O. M., Khalili, S., Wang, R. W., et al. (2013). Paracrine effects of bone marrow soup restore organ function, regeneration, and repair in salivary glands damaged by irradiation. PloS one, 8(4), e61632.

Venkatesh, S. G., Goyal, D., Carenbauer, A. L., \& Darling, D. S. (2011). Parotid secretory protein binds phosphatidylinositol $(3,4)$ bisphosphate. Journal of Dental Research, 90(9), 1085-1090.

Venkatesh, S. G., Tan, J., Gorr, S. U., \& Darling, D. S. (2007). Isoproterenol increases sorting of parotid gland cargo proteins to the basolateral pathway. American journal of physiology. Cell Physiology, 293(2), C558565.

Welsh, J. P., Patel, K. G., Manthiram, K., \& Swartz, J. R. (2009). Multiply mutated Gaussia luciferases provide prolonged and intense bioluminescence. Biochemical and Biophysical Research Communications, 389(4), 563-568.

Yoshida, S., Ohbo, K., Takakura, A., Takebayashi, H., Okada, T., Abe, K., et al. (2001). Sgn1, a basic helix-loop-helix transcription factor delineates the salivary gland duct cell lineage in mice. Developmental Biology, 240(2), 517-530.

Zhang, Y., Ou, D., Gu, Y., He, X., Peng, W., Mao, J., et al. (2013). Diffusionweighted MR imaging of salivary glands with gustatory stimulation: comparison before and after radiotherapy. Acta Radiologica. 


\section{CURRICULUM VITAE}

NAME: $\quad$ lan Scot Pyle

ADDRESS: Department of Oral Health and Rehabilitation

University of Louisville School of Dentistry

501 S. Preston Street

Louisville, KY 40202

DOB: $\quad$ Indianapolis, Indiana - April 5, 1986

EDUCATION

\& TRAINING: $\quad$ B.A., History

Hanover College

2004-08

RESEARCH PROJECTS AND AWARDS:

- Research!Louisville 2012 - Poster Presentation, entitled "Molecular Mechanism of Regulated Exocrine Secretion." August 24 